\title{
Fine Tuning the Use of Second Generation Antipsychotics
}

\section{Priyanka Patil, Thomas L. Schwartz*}

Dept of Psychiatry, SUNY Upstate Medical University, Syracuse, New York

Article Info

\section{Article Notes}

Received: May 14, 2018

Accepted: October 18, 2018

\section{*Correspondence:}

Prof. Thomas L. Schwartz, Dept of Psychiatry, SUNY Upstate Medical University, 750 E, Adams Street, Syracuse, New York 13210; Telephone No: 315-464-3166, 315-464-3163; Email: schwartt@upstate.edu.

(C) 2018 Schwartz TL. This article is distributed under the terms of the Creative Commons Attribution 4.0 International License.

\section{Keywords:}

Second generation antipsychotics

Atypical antipsychotics

Therapeutic Drug Monitoring

Pharmacokinetics

Pharmacodynamics

High dosing

Dose equivalence

Schizophrenia

Antipsychotics

Equivalency

Plasma levels

\section{Abstract}

Background: The standard of care for schizophrenia treatment is the class of medications called the second generation antipsychotics (SGA). However, response rates of schizophrenia to SGA are far from ideal, and approximately one third of patients are likely to need high dosing, polypharmacy or switching of antipsychotics. To do this safely, clinicians' knowledge of SGA pharmacodynamics, pharmacokinetics, therapeutic drug monitoring (TDM) levels, as well as, dose equivalency is imperative.

Aims:

- To review standard dosing, pharmacokinetic, and pharmacodynamic properties of the SGA.

- To further review the use of high, or "super-dosing", of SGA.

- To investigate the clinical importance of monitoring drug levels for SGA.

- To describe possible SGA dose equivalency.

Materials and Methods: A Medline, PubMed (including observational studies, randomized controlled trials, meta-analyses, and systematic reviews) and textbook review was conducted without any date or language restriction. Each SGA (risperidone, paliperidone, lurasidone, ziprasidone, iloperidone, olanzapine, quetiapine, asenapine, aripiprazole, brexpiprazole and cariprazine) was searched and cross referenced with higher dosing, TDM, pharmacodynamics and pharmacokinetics. All possible studies were included. This paper focused on schizophrenia and use of SGA by oral route. Clozapine was excluded. Although it is an SGA, its properties and efficacy are different enough from other SGA and were felt beyond the scope of this current paper.

Discussion: A discussion of the concepts of pharmacokinetic failure, pharmacodynamic failure, Therapeutic Drug Monitoring, SGA dosing equivalencies and super dosing of SGA monotherapies is presented. SGA have pharmacodynamic and pharmacokinetic profiles which are distinctive and lead to unique side-effect profiles, drug-drug interactions, and clinical effects. For example, a SGA such as olanzapine, quetiapine and ziprasidone have evidence that high dosing is of value. Also, TDM drug monitoring is more clinically relevant in certain SGA like olanzapine, quetiapine, and risperidone. These differences are critically delineated.

Summary: This review article allows for a formal, evidence-based discussion regarding several advanced psychopharmacologic concepts which should allow the individual prescriber to elevate their prescribing practices.

\section{Introduction}

Antipsychotics are commonly classified as typical or firstgeneration antipsychotics, (FGA) and atypical or second-generation antipsychotics (SGA). The SGA antagonize dopamine-2 and serotonin-2A receptors where they classically have less potential to cause extrapyramidal symptoms (EPS). The SGA may be more beneficial for mood improvement and may carry a higher metabolic 
side effect risk profile. SGA are now used as first line treatments for psychotic and bipolar disorders per most treatment guidelines. They are secondarily used for other mood and autism spectrum disorders. The Food and the Drug Administration (FDA) has recommendations for SGA dosing including the starting dose, target dose and maximum dose. However about 30 percent of patients will not respond to standard regimens and more heroic dosing strategies or complex polypharmacy approaches may have to be employed. Patients who exhibit hostility or aggression often are prescribed higher than recommended doses especially in inpatient forensic and state hospital settings ${ }^{1}$. When the standard regimented dosing protocols fail, the art of psychopharmacology may need to be applied to achieve symptomatic remission.

The FDA has approved standard dosing for each of the SGA. However, these are based on studies completed with more stable psychiatric populations and are sometimes not adequate for informing clinicians how to treat the outliers: patients who are aggressive, assaultive, disruptive of the milieu, who have high comorbidity, or for patients who seem to clinically not respond to standard protocols ${ }^{2}$. This may lead to unmitigated psychosis for the patient and a sense of helplessness for clinicians. In such situations, clinicians are faced with the dilemma of increasing the dose of SGA (possibly beyond the approved dose), starting antipsychotic polypharmacy (which is frowned upon by current guidelines) or to switch to a different SGA. Therapeutic drug monitoring (TDM) may be used to differentiate pharmacodynamic (the medication does not address the actual biological cause of symptoms) vs pharmacokinetic failure (the SGA is not dosed correctly/ therapeutically) to address some of these situations. Clinicians also have to be aware of the side-effects that may increase with higher dosing or with polypharmacy. Side effects that were commonly encountered in FGA due to their property of unmitigated D2 receptors blockade (ex. acute parkinsonism, akathisia, withdrawal dyskinesias [D2 blockade rebound], tardive dyskinesia [D2 receptor super sensitization], hyperprolactinemia, seizures, cognitive impairment) are less commonly seen in $\mathrm{SGA}^{3}$. This is due to SGA having 5HT-2A serotonin receptor blockade which increases nigrostriatal dopamine. It is also related to possibly more rapid dissociation of SGA from dopamine receptors where dopamine antagonism is enough for antipsychotic effect but not enough for EPS. Hence SGA with higher affinity, with tighter D2 binding (aripiprazole, cariprazine, lurasidone) have higher chances of motor side effects, while SGA with rapid dissociation and lower potency (quetiapine) have lower risk of motor side effects. Although the risk of motor side-effects is decreased, the risk of metabolic syndrome (weight gain, diabetes mellitus, hypercholesterolemia, and hypertension) increases, especially in SGA with $\mathrm{H} 1$ and 5HT-2C serotonin receptor antagonist properties ${ }^{4}$. Cardiovascular events and liver, or pancreatic dysfunction may happen secondary to metabolic syndrome. Some SGA can independently cause liver dysfunction, myocarditis, and neutropenia (direct effects). H1 histamine receptor blockade can lead to sedation as well as binge eating, impulse control disorder and gambling. $\alpha 1$ adrenergic receptor blockade leads to hypotension, fatigue and sexual dysfunction. Anticholinergic blockade can lead to dry mouth, dental caries as well GI side effects and can contribute to cognitive impairment. Hyperprolactinemia can lead to weight gain, sexual dysfunction, as well as osteoporosis and osteopenia leading to fractures. Pneumonia and acute respiratory failure may occur due to central sedation while pulmonary embolism and venous thromboembolism may occur due to hypercoagulability ${ }^{3}$ (Table 2).

Besides providing informed consent to patients when using aggressive clinical strategies, it is important for the clinician to have a framework within which they can apply these practices safely. It is also important to remember that most psychosocial interventions (CBT, family intervention, social skills, and cognitive remediation) may help to decrease core symptoms, alleviate residual symptoms, improve social functioning, increase treatment adherence, lower relapse and decrease hospitalization ${ }^{5,6}$. These when used early in conjunction with antipsychotics may lead to lower dosage possibly of the antipsychotics ${ }^{7}$.

A general treatment algorithm regarding higher dosing of antipsychotics has been recommended by Morrissette and Stahl ${ }^{1}$. This algorithm starts a theoretical clinical discussion which is the basis for this article and serves as a cutting-edge update regarding SGA prescribing. As an example, for a patient who has had a 4 to 6-week trial of a SGA with dose titration per the FDA with an inadequate treatment response, clinicians should obtain a trough plasma level for the SGA. If it is within the therapeutic range, and treatment adherence can be ensured, then consider this now a pharmacodynamic failure ${ }^{8}$. In this case, the drug dosing achieved good plasma levels and then failed to alleviate symptoms. Alternatively, some patients may require extra D2 receptor antagonism, and a slightly higher, off-label dose can be utilized if there are no concomitant excessive side effects. However, sometimes, when drug levels are within therapeutic range (often towards the mid to lower end) without side effects, then pharmacodynamic failure may not have occurred and super dosing to the upper level limits or above may be considered. Of course, if the SGA is within therapeutic range and adverse effects are present then switching to a different SGA may be considered. Finally, if drug levels fall below the proposed therapeutic levels, regardless of approved dosing, a pharmacokinetic failure likely has occurred (rapid metabolizers) and super dosing should be 
considered more routinely ${ }^{9}$. Antipsychotic polypharmacy should only be tried after the above approaches have been undertaken ${ }^{10}$.

\section{Clinical Updates and Discussion}

\section{Pharmacokinetics}

Pharmacokinetics relates to what the body does to each SGA. How the drug is absorbed, distributed, metabolized and excreted is influenced by many factors including: age, gender, disease, pregnancy, pharmacokinetic genotype, interactions with other drugs, diet and sometimes smoking ${ }^{11}$.

SGA exhibit many similar pharmacokinetic characteristics. Important among these are good absorption from the gastrointestinal tract into the blood stream reaching maximal concentrations within 1-6 hours; variable systemic bioavailability (fraction absorbed) ranging from 5 to essentially $100 \%$, fast distribution from the blood into the central nervous system, often higher levels in brain CSF than in blood plasma; elimination mainly by hepatic metabolism/excreted renally, elimination halflife mostly between 12-36 hours, use of cytochrome P450 (CYP) and UDP-glucuronosyltransferases (UGT) as major metabolic enzyme systems ${ }^{11}$. Of course, there are exceptions to the rule. For example, with quetiapine or ziprasidone; they display short (about 2-10 hour) elimination halflives, whereas longer elimination half-lives of 72 hours are noted for aripiprazole, 91 hours for brexpiprazole and 4896 hours for cariprazine (Table 1).

The main antipsychotic effects of the SGA are derived from their $60-80 \%$ antagonism of D2 receptors in the mesolimbic dopamine pathway ${ }^{12}$. Beyond $80 \%$ blockade is the nigrostriatal pathway often leads to EPS ${ }^{13}$. This D2 occupancy can be measured most exactly with PET scanning; but may be more easily measured in clinical practice with plasma antipsychotic levels (TDM) ${ }^{14}$. Pharmacokinetic failure occurs when patients do not reach the estimated 60 percent blockade on standard SGA dose. Some patients may require $61-80 \%$ blockade, again suggesting that high SGA dosing is needed. If plasma levels are within therapeutic level, then the SGA can be dosed higher to maximize the level. Low plasma levels would suggest less than adequate drug concentrations available to bind 60 percent or more of the available D2 receptors.

There are number of factors that lead to this inter and intra-individual pharmacokinetic variability and may cause differences in plasma concentrations. Gender and age may play a role in these variabilities ${ }^{15}$. Female sex hormones may influence the pharmacokinetic process and may lead to differences in efficacies of psychotropics as well ${ }^{16,17,18}$. In the elderly, renal excretion and liver function may decrease significantly, glomerular filtration, tubular reabsorption, and secretion, weight and volume of distribution all change with age as well. For example, hepatic clearance can be reduced by up to $30 \%$, which is mainly explained by lessened hepatic blood flow ${ }^{19}$. Clinically, dosing needs to be adjusted up or down in these cases. TDM may guide clinicians in these situations.

Most SGA undergo Phase 1 hepatic metabolism by oxidative, reductive, and hydrolytic enzymes which are predominantly catalyzed by CYP hepatic enzymes (Table 1). Genetic polymorphism influences CYP enzyme activity but may also reduce with age or be affected by renal or hepatic disease ${ }^{20,21}$. CYP enzymes (especially CYP2D6) are vulnerable to mutation as previously noted. This leads to large inter-individual variability of drug concentrations in the body. Some patients are rapid versus slow metabolizers which can drastically change the half-life and clearance for the drug and change its plasma concentration leading to adverse reactions in slow metabolizers (increased) and non-response in rapid metabolizers (decreased) ${ }^{20,21,22}$.

\section{Table 1. Pharmacokinetics of SGA}

lists the pharmacokinetics of all the SGA (except clozapine). It relates to therapeutic doses of the SGA. It includes oral bioavailability with and without food, half life, protein binding and major cytochrome P450 (CYP) isoenzymes responsible for metabolism. - denotes that oral bioavailability is not affected by food. The major source of reference for this data was online packet insert for each individual drug as well as the book "the Second generation Antipsychotics : A review of current treatment indications and dosing strategies"."

\begin{tabular}{|l|c|c|c|c|c|}
\hline & Oral bioavailability \% & Oral bioavailability with food & Half life & Protein binding & Metabolism \\
\hline Risperidone & 70 & - & 3 & 89 & CYP2D6 \\
\hline Paliperidone & 28 & 42 & 24 & 74 & No CYP interaction \\
\hline Ziprasidone & $\sim 30$ & 60 & 7 & $>99$ & CYP3A4 \\
\hline lloperidone & 96 & - & 18 & 93 & CYP2D6, CYP3A4 \\
\hline Lurasidone & $9-19$ & $18-38$ & 18 & $>99$ & CYP3A4 \\
\hline Olanzapine & 87 & - & 70 & 93 & CYP2D6, CYP1A2 \\
\hline Quetiapine & 9 & - & 24 & 93 & CYP3A4 \\
\hline Asenapine & 35 & - & 75 & $>99$ & CYP1A2 \\
\hline Aripiprazole & 87 & - & 91 & $>99$ & CYP2D6, CYP3A4 \\
\hline Brexpiprazole & 95 & - & $48-96$ & $97 \%$ & CYP2D6, CYP3A4 \\
\hline Cariprazine & High & - & & & CYP3A4 \\
\hline
\end{tabular}


When combining drugs that are inhibitors or inducers of drug metabolizing enzymes, pharmacokinetic drugdrug interactions may occur if the SGA is a substrate of the inhibited or induced hepatic enzyme. These pharmacokinetic interactions occur mostly at the metabolic level and involve changes in activity of CYP. Antidepressants (mostly inhibitors of CYP2D6 such as fluoxetine/ paroxetine) and antiepileptics (inducers of CYP1A2 and CYP3A4 such as carbamazepine) are a major source of these interactions. For example, these SSRIs increase plasma levels of risperidone/aripiprazole/brexpiprazole (substrates for CYP2D6) while, carbamazepine greatly reduces it. Similarly, olanzapine (substrate for CYP1A2) levels are increased with fluvoxamine which is a CYP1A2 inhibitor and decreased with carbamazepine. Quetiapine (substrate for CYP3A4) levels are increased with valproate and decreased with carbamazepine and phenytoin (CYP1A2 and CYP3A4 inducers); aripiprazole (substrate for CYP2D6) is decreased with valproate and ziprasidone (substrate for CYP3A4) is decreased with carbamazepine ${ }^{23,24}$ (Table 1). SGA with high oral bioavailability are less likely to be affected by diet changes or first pass metabolism drugdrug interaction ${ }^{25}$. Also, SGA are often highly protein bound.(Table 1) Co-administration with other drugs which are also highly protein bound (furosemide, spironolactone, ibuprofen, valproic acid etc) may lead to displacement of the antipsychotics and may increase their plasma level.

Finally, smoking is associated with induction of CYP1A2 and may influence elimination of SGA, such as olanzapine, whose metabolism is mainly dependent on CYP1A2 ${ }^{23}$. This is especially important if a patient is smoking more than 10 cigarettes per day. Cessation of heavy smoking (as occurs often while inpatient) under therapy with a CYP1A2 substrate such as olanzapine may require dose reduction ${ }^{26}$. If smoking escalates later during outpatient treatment, then the dose must be escalated to avoid psychotic breakthrough symptoms. Pharmacokinetics of individual SGA are reviewed in Table 1.

\section{Pharmacodynamics}

Pharmacodynamics regarding the SGA include their mechanism of action, especially their effects on neurotransmitters and their receptors. (Table 2) This may be additionally influenced by neurogenesis, neurodevelopment/migration and pharmacogenomics ${ }^{11,27}$. For some patients with psychosis who are taking SGA, there may be no symptom relief with continued psychosis despite even antagonism of $80 \%$ of their D2 receptors. This could be attributed to "pharmacodynamic" failure ${ }^{8}$. Despite achieving adequate plasma drug levels and receptor binding, treatment resistant patients might continue with positive, cognitive and/or aggressive symptoms. The D2 receptor antagonism mechanism of the specific SGA has now failed to provide a therapeutic clinical response regardless of an appropriate pharmacokinetic attempt. In other words, the patient's psychosis, likely is not caused solely by $\mathrm{D} 2$ receptor pathology or an aberrance of the mesolimbic dopamine pathway. The SGA has not addressed the real cause of disease.

Genetic factors can drive pharmacodynamic processes such as interactions of specific SGA with the patient's genetically determined receptor, enzyme, transporter, carrier protein, or ion channels. Specific sensitivity or protein conformation for all of these are involved in mediating SGA treatment outcome which leads to variability in drug response at the level of the individual patient. Sometimes called "a sample size of one, $n=1$ ". For example, there may be a lack of D2 receptor sensitivity or even hypersensitivity. In psychotic disorders, variation in the dopamine receptor genes (DRD2, DRD3 and DRD4) have extensively been investigated regarding antipsychotic treatment response ${ }^{28}$. Oftentimes genetic studies, however, do not yield robustly replicable results. Dystonia and TD which may be induced by SGA have been associated with gene variations as well. An example of pharmacogenomics is association of antipsychotic induced development or worsening of Parkinsonism with polymorphisms of RGS2 (regulator of G-protein signaling 2), a gene which plays a role in dopamine receptor signaling ${ }^{29}$. Pharmacodynamics of individual SGA are reviewed in Table 2.

\section{Super Monotherapy Dosing of SGA}

The Research on East Asia Psychotropic Prescription (REAP) study reported that the factors associated with higher dosages of antipsychotic use were younger age, multiple previous admissions to hospital, presence of active delusions and antipsychotic polypharmacy ${ }^{30}$. The Clinical Antipsychotic Trials of Intervention Effectiveness (CATIE) study which compared four SGA including (olanzapine, quetiapine, risperidone and ziprasidone) and the FGA perphenazine found that higher dosing may be needed in patients with chronic schizophrenia ${ }^{31}$. Another study also reported and explained that "heroic measures", such as high SGA dosing and antipsychotic polypharmacy, are often used in more treatment resistant cases of psychotic disorder when aggression and impulsivity are a key safety concern. This also occurs when pharmacokinetic and pharmacodynamic failures are suspected ${ }^{32}$. Yet another study noted that elevated dosing occurs more often with forensic patients diagnosed with schizophrenia and most associated with increased SGA dosage were the presence of ongoing delusions and conceptual disorganization ${ }^{1,33}$. Accordingly, as positive symptoms intensify and/or are refractory to treatment, doses are naturally increased. Overall, studies show that the practice of using high dose antipsychotics is increasing and is often associated with antipsychotic polypharmacy ${ }^{34}$. 


\section{Table 2. Pharmacodynamic Receptor Actions of SGA}

outlines the general pharmacodynamic properties of the SGA. a. Denotes theoretical off label application. D2 is Dopamine D2 receptor. D3 is Dopamine D3 receptors. 5HT1a is serotonin 1a receptor. 5HT2a is serotonin 2a receptor. 5HT2c is Serotonin 2c receptor. 5HT6 is Serotonin 6 receptor. $5 \mathrm{HT7}$ is Serotonin 7 receptor. $\alpha 1$ is Alpha adrenergic 1 receptor. $\alpha 2$ is Alpha adrenergic 2 receptor. M1 is Muscarinic acetylcholine 1 receptor. $\mathrm{H} 1$ is histamine 1 receptor. NET is Norepinephrine transporter. SERT is Serotonin receptor. Key references for the pharmacodynamic section is from the textbook Stahl's essential psychopharmacology and from the research article by Solmi et al ${ }^{3,67}$.

\begin{tabular}{|c|c|c|c|}
\hline Receptor Action & Clinical effects & Clinical application & Example SGA \\
\hline $\begin{array}{l}\text { D2 } \\
\text { Antagonism }\end{array}$ & $\begin{array}{l}\text { Sexual dysfunction (Hyperprolactinemia) } \\
\text { Akathisia, dystonia, NMS, } \\
\text { Parkinsonism,withdrawal dyskinesia, TD } \\
\text { Avolition, cognitive impairment, weight } \\
\text { gain, seizures }\end{array}$ & $\begin{array}{l}\text { Antipsychotic } \\
\text { Antimanic } \\
\text { Anti-Aggression }\end{array}$ & $\begin{array}{l}\text { Lurasidone, Asenapine, Paliperidone, Risper- } \\
\text { idone, Ziprasidone, lloperidone, Olanzapine, } \\
\text { Quetiapine }\end{array}$ \\
\hline $\begin{array}{l}\text { D2 partial } \\
\text { Agonism }\end{array}$ & $\begin{array}{l}\text { Same as above minus } \\
\text { avolition }\end{array}$ & $\begin{array}{l}\text { Same as above plus } \\
\text { Antidepressant }\end{array}$ & Aripiprazole, Brexpiprazole, Cariprazine ${ }^{a}$ \\
\hline $\begin{array}{l}\text { D3 partial } \\
\text { Agonism }\end{array}$ & $\begin{array}{l}\text { Less EPS possible, } \\
\text { Improved cognition, attention, concen- } \\
\text { tration } \\
\text { Improved wakefulness }\end{array}$ & $\begin{array}{l}\text { Anti-restless leg syndrome } \\
\text { Antidepressant }\end{array}$ & Aripiprazole $^{\mathrm{a}}$, Brexpiprazole ${ }^{\mathrm{a}}$, Cariprazine ${ }^{\mathrm{a}}$ \\
\hline $\begin{array}{l}\text { 5HT1a partial } \\
\text { agonism }\end{array}$ & Reduce negative affect & $\begin{array}{l}\text { Anxiolytic } \\
\text { Antidepressant }\end{array}$ & $\begin{array}{l}\text { Aripiprazole, Lurasidone, Asenapine }{ }^{a} \text {, Ziprasido- } \\
\text { ne }^{a} \text {, Cariprazine }{ }^{a} \text {, Brexpiprazole }\end{array}$ \\
\hline $\begin{array}{l}5 \mathrm{HT} 2 \mathrm{a} \\
\text { antagonism }\end{array}$ & $\begin{array}{l}\text { Reduce EPS } \\
\text { Reduce negative affect } \\
\text { Improve sleep efficiency }\end{array}$ & Antidepressant, hypnotic & 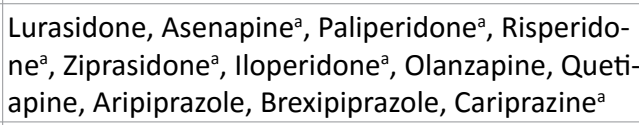 \\
\hline $\begin{array}{l}\text { 5HT2c antago- } \\
\text { nism }\end{array}$ & $\begin{array}{l}\text { Reduce negative affect } \\
\text { Decrease metabolism } \\
\text { Improve cognition, weight gain }\end{array}$ & Antidepressant & $\begin{array}{l}\text { Asenapine }^{\mathrm{a}} \text {, Ziprasidone }{ }^{\mathrm{a}} \text {, Olanzapine, Quetiapine } \\
\text { Aripiprazole, Brexipiprazole, Cariprazine }^{\mathrm{a}}\end{array}$ \\
\hline 5HT6 antagonism & Entrain circadian rhythm & ----- & Asenapine $^{a}$, lloperidone ${ }^{a}$ \\
\hline 5HT7 antagonism & $\begin{array}{l}\text { Entrain circadian rhythm } \\
\text { Improve cognition }\end{array}$ & $\begin{array}{l}\text { Antidepressant, anti-neg- } \\
\text { ative symptoms, circadian } \\
\text { rhythm, memory, learning } \\
\text { and sleep }\end{array}$ & $\begin{array}{l}\text { Lurasidone, Asenapine }^{\text {a }} \text {, lloperidone } \\
\text { Brexpiprazole, Aripiprazole }\end{array}$ \\
\hline$\alpha 1$ antagonism & Orthostasis, sedation & $\begin{array}{l}\text { Antihypertensive } \\
\text { Anxiolytic } \\
\text { Anti-nightmares }\end{array}$ & $\begin{array}{l}\text { Risperidone }{ }^{a}, \text { lloperidone }^{a}, \text { Asenapine, Olanzap- } \\
\text { ine }^{a} \text { Quetiapine }^{\mathrm{a}}, \text { Aripiprazole }^{\mathrm{a}} \text {, Brexipiprazole } \\
\text { Cariprazine }^{\mathrm{a}}\end{array}$ \\
\hline$\alpha 2$ antagonism & Same as above plus improved cognition & $\begin{array}{l}\text { Anti-ADHD } \\
\text { Antihypertensive } \\
\text { Anxiolytic } \\
\text { hypnotic }\end{array}$ & Risperidone ${ }^{a}$, Paliperidone, Asenapine \\
\hline M1 antagonism & $\begin{array}{l}\text { Dry mouth, dental caries blurred vision, } \\
\text { nausea, vomiting, diarrhea and consti- } \\
\text { pation, worsened cognition, tachycardia, } \\
\text { urinary retention }\end{array}$ & Anti- EPS & $\begin{array}{l}\text { Olanzapine }{ }^{a}, \text { Aripiprazole }^{a}, \text { Brexipiprazole } \\
\text { razine }^{\mathrm{a}} \text {, Carip- }\end{array}$ \\
\hline $\mathrm{H} 1$ antagonism & $\begin{array}{l}\text { Somnolence, weight gain increased } \\
\text { appetite, binge eating, impulse control } \\
\text { disorder and gambling, }\end{array}$ & Anxiolytic, hypnotic & $\begin{array}{l}\text { Olanzapine }{ }^{a}, \text { Quetiapine }^{a}, \text { Asenapine } \\
\text { zole }^{a}, \text { Aripipra- } \\
\text { Brexipiprazole }{ }^{a}, \text { Cariprazine }^{a}\end{array}$ \\
\hline NET inhibition & $\begin{array}{l}\text { Increase wakefulness } \\
\text { Improved cognition, attention, concen- } \\
\text { tration } \\
\text { Reduce negative affect }\end{array}$ & $\begin{array}{l}\text { Anxiolytic, antidepressant, } \\
\text { Anti-ADHD }\end{array}$ & Ziprasidone ${ }^{a}$, Quetiapine \\
\hline SERT inhibition & Reduce negative affect & Anxiolytic, antidepressant & Ziprasidone $^{a}$ \\
\hline
\end{tabular}

As mentioned previously, definite pharmacokinetic or possible pharmacodynamic failures may make high SGA dosing necessary to obtain possibly greater symptom control. To review, due to patient individual variability, a patient may not achieve a $60 \%$ D2 receptor blockade on standard dose, and he/she likely would continue to exhibit psychotic symptoms at which point higher than approved dosing may be beneficial and likely warranted in this specific clinical situation. If plasma levels are low, then super dosing likely should be standard of care. If a patient has achieved greater than $80 \%$ blockade or is at maximal approved dosing with maximal plasma levels on standard dose and continues to exhibit positive psychotic symptoms (especially if side-effects are present), then a 
pharmacodynamic failure has occurred. For some treatment refractory patients, who have several pharmacokinetic/ pharmacodynamic failures well beyond the assumed $80 \%$ blockade, then using heroic elevated SGA dosing may be needed for these outlying cases (especially if they do not manifest EPS, QTc prolongation, etc.). In fact, literature seems to suggest that a significant portion of patients could tolerate dosing beyond normal ranges ${ }^{32}$.

New prescribers always must balance the concept that with increased dosage comes the risk of increased side effect burden. For SGA this includes metabolic syndrome (weight gain, diabetes mellitus, hypertension), QTc prolongation, EPS and TD. Therefore, it is always recommended to start low within the FDA approved range to minimize initial side effects, facilitate adherence and then to build rapport along with escalations in dosing. Only about $20 \%$ of patients respond within a few weeks. Earlier monitoring of plasma levels and confirming diagnosis are some steps that may be utilized at this clinical juncture. Next, pharmacokinetic failure should be considered. Only after these have occurred and informed consent given; SGA can be slowly increased outside the dosage recommended by the FDA. The end point would be either clinical effect or unbearable/unsafe sideeffects $^{32}$. High dosing is reviewed in Table 3.

\section{Therapeutic Drug Monitoring (TDM) with SGA}

The therapeutic reference range is defined as the range of drug concentrations in blood that suggests a lower limit below which a drug induced therapeutic response is relatively unlikely to occur and an upper limit above which tolerability decreases or where it is relatively unlikely that therapeutic improvement will occur.

\section{Table 3. SGA Dosing and TDM Levels}

This table includes Food and Drug administration (FDA) approved treatment indications and dosing strategies (initial dose, titration dose, target dose and maximum dos). All except high dosing strategies was garnered from regulatory package inserts. For high dosing multiple sources were used. Key reference was book by O'Dell and Schwartz on second generation antipsychotics ${ }^{4}$. Other key references were from articles by Citrome et al, Morrissette et al, Stahl et al and Moore et al ${ }^{1,32,66,82,83,99,100}$. As it is still debated whether TDM should be routinely used in clinical situations AGNP came up with 4 levels of recommendations based on empirical evidence. Level 1 is strongly recommended; Level 2 is recommended, Level 3 is Useful and Level 4 is Potentially useful. These levels of recommendations are more thoroughly explained in the text related to $\mathrm{TDM}^{11}$. Alert levels: are levels of the drug to warn the physician when the drug concentrations are considered to be too high and potentially harmful. As per the article alert levels should lead to dose reduction if patient exhibits adverse reaction. Abbreviations: bid, twice daily.

\begin{tabular}{|c|c|c|c|c|c|c|c|c|}
\hline & Initial dose & Titration & Target dose & $\begin{array}{l}\text { Maximum } \\
\text { dose }\end{array}$ & High dosing & $\begin{array}{c}\text { TDM } \\
\mathrm{ng} / \mathrm{ml}\end{array}$ & $\begin{array}{l}\text { Levels of recom- } \\
\text { mendations as } \\
\text { per AGNP }\end{array}$ & $\begin{array}{l}\text { Alert } \\
\text { levels } \\
\mathrm{ng} / \mathrm{ml}\end{array}$ \\
\hline Risperidone & $1 \mathrm{mg} / \mathrm{day}$ & $1-2 \mathrm{mg} /$ day & 4-6 mg/day & $16 \mathrm{mg} /$ day & $\begin{array}{l}\text { Higher doses not } \\
\text { tolerated }\end{array}$ & $20-60$ & 2 & 120 \\
\hline Paliperidone & $6 \mathrm{mg} /$ day & $3 \mathrm{mg} / 5$ day & $6 \mathrm{mg} /$ day & $12 \mathrm{mg} /$ day & $\begin{array}{l}\text { Higher doses not } \\
\text { tolerated }\end{array}$ & $20-60$ & 2 & 120 \\
\hline Ziprasidone & $20 \mathrm{mg}$ bid & $200 \mathrm{mg}$ bid/ 2 day & $20-80 \mathrm{mg}$ bid & $100 \mathrm{mg}$ bid & $\begin{array}{l}\text { Studies show efficacy } \\
\text { up to } 360 \mathrm{mg} / \text { day }\end{array}$ & $50-200$ & 2 & 400 \\
\hline Iloperidone & $1 \mathrm{mg}$ bid & $\begin{array}{l}2,4,6,8,10,12 \\
\text { mg bid on days } \\
2,3,3,5,6 \& 7\end{array}$ & $6-12 \mathrm{mg}$ bid & $12 \mathrm{mg}$ bid & $\begin{array}{l}\text { Limited data for high } \\
\text { dosing, for safety has } \\
\text { been studied up to } \\
32 \mathrm{mg}\end{array}$ & $5-10$ & 3 & 20 \\
\hline Lurasidone & 40 mg/day & - & $\begin{array}{l}40-160 \mathrm{mg} / \\
\text { day }\end{array}$ & $160 \mathrm{mg} /$ day & $\begin{array}{l}\text { Limited data for high } \\
\text { dosing. Safety has } \\
\text { been studied up to } \\
600 \mathrm{mg}\end{array}$ & $\begin{array}{l}\text { Higher } \\
\text { than } 70\end{array}$ & 3 & 120 \\
\hline Olanzapine & $5-10 \mathrm{mg} /$ day & $5 \mathrm{mg} / 1$ week & $10 \mathrm{mg} / \mathrm{day}$ & $20 \mathrm{mg} / \mathrm{day}$ & $\begin{array}{l}\text { Forensic settings up } \\
\text { to } 90 \mathrm{mg} / \text { day }\end{array}$ & $20-80$ & 1 & 150 \\
\hline $\begin{array}{l}\text { Quetiapine } \\
\text { IR/XR }\end{array}$ & $\begin{array}{l}25 \mathrm{mg} \text { bid } \\
/ 300 \mathrm{mg} / \text { day }\end{array}$ & $50-300 \mathrm{mg} /$ day & $\begin{array}{l}400-800 \mathrm{mg} / \\
\text { day }\end{array}$ & $800 \mathrm{mg} /$ day & $\begin{array}{l}\text { Forensic settings up } \\
\text { to } 1800 \mathrm{mg} / \text { day }\end{array}$ & $100-500$ & 2 & 1000 \\
\hline Asenapine & $5 \mathrm{mg}$ bid & $5 \mathrm{mg}$ bid/1 week & $5 \mathrm{mg}$ bid & $10 \mathrm{mg}$ bid & Not well studied & $2-5$ & 4 & 10 \\
\hline Aripiprazole & $10-15 \mathrm{mg} /$ day & $5 \mathrm{mg} / 2$ weeks & $\begin{array}{l}10-15 \mathrm{mg} / \\
\text { day }\end{array}$ & $30 \mathrm{mg} /$ day & $\begin{array}{l}\text { Higher dosing usually } \\
\text { not more effective } \\
\text { and possibly less } \\
\text { effective }\end{array}$ & $150-500$ & 2 & 1000 \\
\hline Brexpiprazole & $1 \mathrm{mg} /$ day & $\begin{array}{l}2 \mathrm{mg} / \text { day on day } \\
5,4 \mathrm{mg} \text { on day } 8\end{array}$ & $2-4 \mathrm{mg} /$ day & $4 \mathrm{mg} / \mathrm{day}$ & No data & $40-140$ & 3 & 280 \\
\hline Cariprazine & $1.5 \mathrm{mg} /$ day & $\begin{array}{l}3 \mathrm{mg} / \text { day on day } \\
2,1.5-3 \mathrm{mg} / \text { sever- } \\
\text { al weeks }\end{array}$ & $\begin{array}{l}1.5-6 \mathrm{mg} / \\
\text { day }\end{array}$ & 6 mg/day & No data & $10-20$ & 3 & 40 \\
\hline
\end{tabular}


Unlike the well-studied lithium (Bipolar) and tricyclic antidepressant (Depression) blood levels where this clinical approach is well-defined, the SGA have much smaller trials where levels are correlated to standard trial dosing but not necessarily clinical or safety outcomes. However, these levels do suggest what plasma levels of SGA should be achieved with standard dosing and this can guide treatment to some degree.

TDM is a rough measure of the pharmacodynamic and pharmacokinetic aspect of prescribing and also checks for patient non-adherence. It enables further tailoring of SGA dosage for the individual patient by combining the quantification of drug concentrations in blood, information on drug properties and patient characteristics. It can be used for problem solving. For example, it can help differentiate between pseudo drug resistance (characterized by lower plasma levels due to rapid metabolization or poor adherence (aka pharmacokinetic failure) or true drug resistance (appropriate levels with receptors insensitivity aka pharmacodynamic failure).

The clinical importance of having TDM for antipsychotics is still a matter of debate but it can be useful in case of treatment resistance. The D2 occupancy of SGA is indirectly related to TDM levels (plasma SGA level) ${ }^{14}$. SGA Steady-state concentrations in blood tend to correlate with concentrations in brain and ultimately D2 receptor occupancy, much better than they correlate to the prescribed dosages. The TDM task force of the working group on neuropsychopharmacology (Arbeitsgemeinschaft fuer Neuropsychopharmakologie und Pharmakopsychiatrie, AGNP) has divided TDM outcomes into 4 levels: Level 1 (strongly recommended) is for psychotropics like lithium and carbamazepine where TDM is standard of care and highly predictive of outcomes and adverse effects. There is highest possibility of response, when the psychotropic is at high therapeutic concentrations (normal lab value) and, there is risk also of adverse effects and some toxicity. For Level 2 (recommended), ranges were obtained from psychotropics at the therapeutically effective doses and related to ultimate clinical effects. Hence TDM is recommended for dose titration and for special indications or problem solving as mentioned above; TDM will increase the probability of response in non-responders. For SGA at Level 3 (useful) suggests that ranges were computed from drug concentrations at approved doses but not yet linked to clinical outcome. Here, TDM is useful for special indications or problem solving and determining why clinical consequences may have occurred. Clinical improvement may be attained by dose increase in non-responders who display low drug concentrations. For level 4 (potentially useful), drug concentrations in blood do not correlate with clinical effects due to a unique pharmacology of the drug, e. g., irreversible blockade of an enzyme, or dosing can be easily guided by clinical symptoms, e. g., sleep induction by a hypnotic drug. Here, TDM is not recommended for dose titration, but may be potentially useful for special indications or problem solving such as patient adherence ${ }^{11}$. (Table 3) Accordingly, the alert levels are significant if patient has adverse effects, but in case these are absent then the drug can be continued if the risk is symptom relapse ${ }^{11}$ (Table 3). Finally, AGNP also recommends getting a TDM level when the patient is clinically improved (remitted) so that one can have a baseline for individual patients, which can serve as a guideline to differentiate between future non-adherence or pharmacokinetic alteration in case of relapse or side-effects ${ }^{11}$. Later, if needed, the oral or intramuscular dose can be re-titrated to now match the patient's ideal plasma level.

TDM can be used for special indications. There are also certain populations where getting a TDM level can be more useful than others. Elderly patients are more susceptible to side effects and have less functional metabolic reserve ${ }^{35}$. Forensic psychiatric patients with risk of violence and aggressive behavior many times need to be treated with higher doses and a TDM level is highly useful and can be used to delineate their optimal blood levels for symptom control $^{33}$. Also, when an SGA changes from the original brand name to a novel generic preparation, or if one generic is changed to another, the actual dose/bioavailability may fluctuate by $15-20 \%$. TDM can be used to make sure that the new preparation oral dose ultimately achieves the absolute plasma level afforded by the original brand name SGA. This should better ensure a sustained clinical response. TDM of SGA is also useful similarly when an oral SGA is converted to the long acting intramuscular depot formulation or vice versa for similar reasons. The goal is to maintain the optimal plasma level regardless of drug preparation chosen. SGA Dosing, as well TDM, are reviewed in Table 3.

\section{SGA Dosing equivalence}

When managing schizophrenia treatment resistance, violent aggressivity or remarkable adverse effects, SGA switching or the use of first generation antipsychotics (FGA) is often necessary. To choose an appropriate target dose for the new SGA, two methods can be used; either titrating the dose to the maximum effectiveness and stopping when tolerance/side effects emerge or using dose equivalency data. However, the development of valid and reliable methods of dose comparison is yet to be fully realized as compared to first generation antipsychotics (FGA). Various methods have been used to calculate the dose equivalency and can be broadly divided into calculated methods and consensus methods ${ }^{36}$ (Table 4).

Calculated methods can be further divided into; chlorpromazine (FGA) equivalents, the classical mean 


\section{Table 4. This table includes few of the methods of SGA Dosing Equivalency}

The methods are broadly divided as Consensus method and Calculated method. These methods have been explained in the text related to SGA dose equivalence. The SGA are compared to $1 \mathrm{mg}$ equivalence of olanzapine in all the below mentioned, except for the maximal near effective method. The calculated method has been further divided into the chlorpromazine equivalence (Linear equation) method, the daily defined dose, the minimum effective dosing method, the classical mean dose method, and the maximum dose (near effective) method $^{40,42,101,102,103}$. Although the Linear equation method is a calculated method it was derived from a consensus method. The consensus method by Gardner et al reports clinically equivalent dose when compared to $20 \mathrm{mg}$ of olanzapine ${ }^{46}$. The following table shows the doses of SGA equivalent to $1 \mathrm{mg}$ of olanzapine. This comparison was gathered from articles by Patel et al and Leucht et al ${ }^{36,43}$. The daily defined dose for iloperidone and brexipiprazole was taken from WHO website ${ }^{42}$. Based on the formula by Leucht et al to derive doses of SGA that are equivalent to $1 \mathrm{mg}$ of olanzapine ( DDD of the drug/10) the DDD of iloperidone and brexpiprazole were derived and included in the table ${ }^{43}$. Cariprazine has no data available regarding dose equivalence.

\begin{tabular}{|c|c|c|c|c|c|c|}
\hline \multirow[b]{2}{*}{ Drug } & \multirow[b]{2}{*}{ Consensus method } & \multicolumn{5}{|c|}{ Calculated Method } \\
\hline & & Linear equation & $\begin{array}{l}\text { Daily defined } \\
\text { dose }\end{array}$ & $\begin{array}{c}\text { Minimum } \\
\text { effective dose }\end{array}$ & $\begin{array}{c}\text { Classical Mean } \\
\text { dose method }\end{array}$ & $\begin{array}{c}\text { Maximum Near-effective } \\
\text { dose }\end{array}$ \\
\hline $\begin{array}{l}\text { Baseline com- } \\
\text { parator }\end{array}$ & Olanzapine 1 mg & Olanzapine $1 \mathrm{mg}$ & Olanzapine $1 \mathrm{mg}$ & Olanzapine $1 \mathrm{mg}$ & Olanzapine $1 \mathrm{mg}$ & N/A \\
\hline Risperidone & 0.30 & 0.28 & 0.5 & 0.27 & 0.4 & 4 \\
\hline Paliperidone & 0.45 & - & 0.6 & 0.4 & - & - \\
\hline Ziprasidone & 8.00 & 10.48 & 8.00 & 5.33 & 7.9 & $80-160$ \\
\hline Iloperidone & - & - & 1.8 & 1.07 & - & - \\
\hline Lurasidone & - & - & 6 & 5.33 & - & - \\
\hline Olanzapine & 1 & 1 & 1 & 1 & 1 & $>16$ \\
\hline Quetiapine & 37.04 & 29.97 & 40 & 20 & 32.3 & $150-600$ \\
\hline Asenapine & - & - & 2 & 1.33 & 0.9 & - \\
\hline Aripiprazole & 1.49 & 1.34 & 1.5 & 1.33 & 1.4 & 10 \\
\hline Brexpiprazole & - & - & 0.3 & - & - & - \\
\hline Cariprazine & - & - & - & - & - & - \\
\hline Chlorpromazine & 30.30 & 21.31 & 30 & 30 & 38.9 & $400-450$ \\
\hline
\end{tabular}

Abbreviation - Data not available

dose method, the minimum effective dose method, the maximum dose method and the daily defined dose method. Most commonly, chlorpromazine is used as the standard comparative drug.

Chlorpromazine equivalence: Davis in 1974 invented this method for FGA by using chlorpromazine as the standard comparator. Based on randomized, double blind, flexible-dose studies on antipsychotics he identified comparable doses chosen by the clinicians to achieve therapeutic effect. This was then used to calculate dose ratios in relation to $100 \mathrm{mg}$ of chlorpromazine ${ }^{37}$. Leutch et al created the classic mean dose method where he applied Davis classical approach to SGA. They searched randomized double blind flexible dose trials in acutely ill patients with schizophrenia that examined all available oral SGA, haloperidol and chlorpromazine. They then calculated the mean doses of each drug weighted by sample size and divided them by weighted mean olanzapine dose to obtain "an olanzapine equivalent" ${ }^{38}$. Using chlorpromazine equivalents; Woods developed a novel dose equivalency table for SGA in 2003. He identified the minimum effective doses of the then current five SGA and haloperidol from fixed-dose placebo controlled trials. The minimal effective dose is the lowest fixed dose of each SGA that was consistently more efficacious than placebo in the primary outcome. Chlorpromazine equivalents were then derived from identified doses ${ }^{39}$. In 2013 Leutch, based upon a similar principal of minimal effective dosing, calculated the olanzapine equivalent for eight additional SGA. This is called the minimum effective dose method. As a limitation, the results are not applicable to specific populations such as first-episode psychosis versus refractory patients ${ }^{40}$ (Table 4). All the above methods assumed linearity of dose equivalency. These do not account for the fact that a dose response curve is usually sigmoidal in shape. Also, these methods do not take into consideration that SGA can have high degrees of individual patient efficacies as noted earlier.

For the maximum dose method; the near-effective maximum dose which was calculated by Davis \& Chen in 2004 is defined as the threshold dose eliciting clinical response with the lowest adverse profile. It can be calculated from dose-response curves which are constructed using data from fixed-dose randomized placebo-controlled studies. Equivalence between antipsychotics is then established by comparing the neareffective doses. Although this approach does use the dose response curve, it is used in preclinical research and there is inadequate data to construct dose response curves for all SGA as such ${ }^{41}$ (Table 4). The daily defined dose (DDD) was developed by the World Health Organization (WHO) and uses the average, maintenance dose per day per drug for its main indication for comparison. The primary purpose 
of the DDD calculation was essentially to aid comparison of drug utilization, not necessarily to define dose equivalence clinically $^{42}$. A study by Leutch which compared the dose equivalence estimates bases on DDDs with three other methods (minimum effective dose method, classical mean dose method and international expert consensus method ) reported that DDDs should only be used for dose equivalence if other more scientific approaches are not available ${ }^{43}$. The article does not mention the DDD for brexpiprazole and iloperidone. However based on their formula to derive doses of each drug that are equivalent to $1 \mathrm{mg}$ of olanzapine (DDD of the drug/10), the DDD of iloperidone and brexpiprazole is derived and included in Table 4. Regarding the Consensus Method, studies have been completed and use the original SGA, risperidone, as the standard comparative. It heavily relies on the knowledge and experience of experts in the field and may vary over time and hence need reassessment. Even in this method, experts assumed linearity of dose and response. In 2003 Kane et al conducted a survey of 49 experts to estimate equivalencies for fixed dose of haloperidol and risperidone. The authors found that responses "followed a very linear pattern ${ }^{44}$. Based on the guidelines established by Kane et al, Andreasen et al. in 2010 conducted a linear regression analysis (linear equations) in which dose equivalents of haloperidol ( $2 \mathrm{mg}$ ) and chlorpromazine (100 $\mathrm{mg}$ ) were used for comparing the SGA. The formulas were solved for chlorpromazine $100 \mathrm{mg}$ and haloperidol $2 \mathrm{mg}$ to derive new chlorpromazine and haloperidol equivalents of the SGA. The resulting equivalents could also be used to calculate the "dose-years" (100 mg /day of chlorpromazine equivalent or $2 \mathrm{mg} /$ day of haloperidol dose equivalent taken for 1 year is equal to 1 dose year $)^{45}$ (Table 4 ). The most recent consensus by Gardener et al. in 2010 appears to provide the most complete estimation of equivalencies and specific clinical scenarios. In this method respondents (research and clinical experts) were asked to indicate what dose they consider to be clinically equivalent to $20 \mathrm{mg}$ /day of olanzapine in treatment of reference case, a moderately symptomatic adult man with DSM IV schizophrenia with $\geq 2$ years of antipsychotic treatment and not considered treatment refractory. Dosing ratios were than calculated to this dose of olanzapine. The equivalents reported were found to be strongly correlated with the near-effective dose equivalents for ten $\mathrm{SGA}^{46}$ (Table 4). In spite of the limitation of the dose equivalency methods for SGA, they do provide a rough guideline which would be useful when switching of SGA occurs during routine patient care. SGA equivalence are reviewed in Table 4.

\section{SGA Profiles}

\section{Risperidone}

Pharmacodynamics: Risperidone at lower doses antagonizes 5HT2A serotonin receptors (anti-EPS), while at higher dosage antagonizes dopamine receptors (antipsychotic). This is common amongst the SGA. It also antagonizes alpha-1( $\alpha 1)$ norepinephrine receptors leading to possible orthostasis. It has a higher affinity for H1 histamine receptor antagonism and can lead to weight gain and sedation. It is considered most typical of the SGA; possibly due to the poor CNS penetration of risperidone and its active metabolite (paliperidone) it has higher tendency as compared to other SGA to be associated with hyperprolactinemia leading to amenorrhea, galactorrhea, and sexual side-effects ${ }^{47}$. Data indicates that this propensity for prolactin elevation is correlated with the plasma concentrations of the active ( 9 hydroxy risperidone [paliperidone]) metabolite ${ }^{48}$.

Pharmacokinetics: Bioavailability is $70 \%$ and protein binding is $89 \%$. Risperidone undergoes 9-hydroxylation in liver which yields the active ( 9 hydroxy risperidonepaliperidone) metabolite. This metabolite is the active ingredient of the SGA paliperidone. This step is primarily metabolized by CYP2D6 and to a lesser extent CYP3A4. Ultimately the plasma levels are influenced by the genetic variations in the CYP2D6 enzymes (slow/rapid metabolizers $)^{49}$. The half-life for the parent compound is 3 hours in rapid metabolizers and 22 hours in slow metabolizers and that for the active metabolite is 22 hours in both. Concomitant use of enzyme inducers should necessitate doubling of the dose and use of enzyme inhibitors should lead to reductions in dose.

TDM: The CYP2D6 slow vs rapid metabolizers status affects plasma levels of risperidone vs the 9-OHRSP metabolite with extensive metabolizers having a higher plasma level of the active metabolite and poor metabolizers having a lower level ${ }^{50,51}$. Clinical effect is assumed to be due to sum of the parent compound plus its active metabolite. Therefore, monitoring the plasma levels for both the parent risperidone compound and metabolite is recommended. ${ }^{11}$ AGNP-TDM guideline reports therapeutic level for risperidone plus $9-0 H-R S P$ is 20 to $60 \mathrm{ng} / \mathrm{ml}$. Parkinsonian side effects are noted at plasma levels of $74 \mathrm{ng} / \mathrm{ml}$ or higher ${ }^{52}$. TDM is recommended for identification of non-responders and for determination of "sub-therapeutic" plasma concentrations and for "supra therapeutic" concentrations. TDM can help to determine CYP2D6 inhibition due to either genetically impaired CYP2D6 activity or drug interactions. It is also useful to monitor the TDM while switching from injectable to oral form (or vice versa), so that individual patient's ideal plasma level is maintained ${ }^{11}$. A study which examined the long-term pharmacokinetics of risperidone found that risperidone plasma concentration/dose ratio (C/D) accumulation peaked $49 \%$ at 2 months (from baseline concentration) and 9-hydroxy-RSP and total moiety C/D accumulation peaked $66 \%$ at 6 months. This suggests that 
metabolism of the drug may be affected by both CYP2D6 inhibition and DNA regulatory mechanisms ${ }^{53}$. Interestingly PET study data indicate target concentration of 10-15 ng/ $\mathrm{ml}$ for optimal results, and concentration above $40 \mathrm{ng} / \mathrm{ml}$ may be associated with adverse effects. This recommended level is lower than the AGNP guidelines ${ }^{54}$.

High dosing: Dose titration: With respect to dosing strategies in adults with schizophrenia, a typical initial dose is $1.0-2.0 \mathrm{mg} /$ day, with a target dose of $4.0-6.0 \mathrm{mg} /$ day and a maximum dose of $16.0 \mathrm{mg} /$ day.

The FDA approved maximum dose is $16 \mathrm{mg}$. Risperidone reaches 70 to 80 percent of D2 occupancy at doses between 2 to $4 \mathrm{mg} /$ day $^{13,32}$. The risk of EPS increases with dosing and super high dosing has not been recommended ${ }^{55}$. Some studies have reported clinical improvement for some patients for up to $16 \mathrm{mg}$ of risperidone and only $31 \%$ patient who were on $10 \mathrm{mg}$ of risperidone required antiparkinsonism medications. This again suggests a subgroup which may benefit from higher dosing ${ }^{56}$.

\section{Paliperidone}

Pharmacodynamics: It has similar pharmacodynamic profile to parent compound, risperidone, noted just above. Paliperidone antagonizes $\alpha 1$ and $\mathrm{H} 1$ receptors, however the affinity for $\alpha 1$ blockade is lower as compared to risperidone so there is less potential for orthostasis. Paliperidone has no affinity for cholinergic muscarinic or $\beta 1$ - and $\beta 2$-adrenergic receptors. At least one study found that it has lower potential for weight gain when compared to risperidone, quetiapine, aripiprazole and olanzapine $\mathrm{e}^{57}$. It tends to be less sedative and has less potential for EPS as compared to risperidone. This suggests it could theoretically be better tolerated at higher doses ${ }^{55}$.

Pharmacokinetics: Its bioavailability is $30 \%$ and protein binding is $74 \%$. Paliperidone may have a more stable drug concentration due to its OROS (osmotic controlled release oral delivery system) which is a slow release preparation and accounts for less fluctuations in peak to trough plasma levels, leading to lower dose frequency and also improved tolerability. This technology allows the dose to be started at the effective dose and hence initial dose titration is not required ${ }^{58}$. Paliperidone is an extended-release (ER) formulation that is approved for treatment of schizophrenia in adults.

Paliperidone in different than its parent compound, risperidone, pharmacokinetically. Firstly, the halflife of paliperidone is 22 hours both in rapid and slow metabolizers. Secondly, since it undergoes mild hepatic metabolism at most, dose adjustment is typically not required in mild to moderate hepatic impairment. Thirdly, it is glucuronidized and easily metabolized without CYP450, so it has less chance of a drug-drug interaction. As it is primarily easily excreted by the kidneys, lowering the dose in case of renal impairment is recommended ${ }^{59}$.

High dosing: Dose titration: Regarding dosing strategies, an average initial dose in adults with schizophrenia or schizoaffective disorder is $6.0 \mathrm{mg} /$ day (no initial dose titration is needed) with a maximum dose of $12.0 \mathrm{mg} /$ day (Table 1). If dose titration is required, an increment of $3.0 \mathrm{mg} /$ day at intervals of greater than 5 days is recommended.

The FDA approved maximum dose is $12 \mathrm{mg}$. However, 70 to 80 percent D2 occupancy is found at 6 to $9 \mathrm{mg} /$ day and as with risperidone, higher dosing with paliperidone is not often recommended, may not be efficacious and can lead to increased potential for side effects including EPS ${ }^{1,59}$. However, since it has less possible potential for some sideeffects, it can be dosed higher than risperidone ${ }^{27}$.

TDM: AGNP-TDM consensus guidelines range is 20-60 $\mathrm{ng} / \mathrm{ml}$ and recommendation level is 2(recommended). A relationship between plasma concentration at therapeutic levels and clinical effects has been demonstrated, making TDM recommended for dose titration and for specific indications or problem solving when there is initial nonresponse. TDM will increase the probability of response in non-responders. At supratherapeutic levels there is increased risk of intolerance ${ }^{11}$. For patients who are non-responders to parent drug risperidone, who are found to be CYP2D6 deficient, or simply cannot mount high enough 9-OH-RSP levels may benefit more from taking this paliperidone product which requires no metabolism.

\section{Ziprasidone}

Pharmacodynamics: Just like risperidone, ziprasidone antagonizes 5HT2A serotonin receptors at lower dosages and antagonize D2 dopamine receptors at higher dosage. Ziprasidone may have relatively fewer side-effects and has been shown to have a lower risk of metabolic effects and weight gain ${ }^{60,61,62}$. It binds with moderate affinity to $\mathrm{H} 1$ and high affinity to $\alpha 1$. It has little or no affinity to M1 and anticholinergic effect is not significant ${ }^{63}$. Therefore sedation, orthostasis and dizziness may be encountered. Interestingly, ziprasidone has some ability to inhibit norepinephrine and serotonin reuptake but has shown limited antidepressant ability. Ziprasidone may lead to increase in QTc by 15.0-20.0 msec. However serial EkGs are not recommended unless there is history of cardiac problems like congenital QTc prolongation, cardiac arrhythmias, recent MI or heart failure. In these cases, careful use, or avoiding it altogether may be necessary. Also, care should be taken when combing with other QTc prolonging drugs (class $1 \mathrm{~A}$ and class III antiarrhythmics, certain antipsychotics, the fluoroquinolone antibiotics, pentamidine, methadone, and levomethadyl acetate). Monitoring electrolytes would be useful in cases of 
hypokalemia, hypomagnesia, and bradycardia that might prolong the QTc further.

\section{Pharmacokinetics:}

Ziprasidone requires administration with food to maximize absorption and bioavailability ( $60 \%$ with food). It is metabolized primarily by CYP3A4 and to a lesser extent by CYP1A2. The dose should be adjusted with the concomitant use of strong inhibitors or inducers of these enzymes. Age and gender do not play a prominent role its pharmacokinetics ${ }^{63}$. Smoking can affect the plasma levels of ziprasidone, as tobacco is a strong inducer of CYP1A2.

TDM: Improvement or side effects have not clearly correlated significantly with doses or serum levels globally but TDM can be used for individual dose adjustment. Ziprasidone's bioavailability and absorption increases while pharmacokinetic variability decreases with the presence of food. Also serum concentrations of ziprasidone are not dose proportional under fasting states but become dose proportional and more linear under fed states ${ }^{64}$. This is important to take into consideration when measuring the TDM. AGNP TDM guidelines quote a reference range of $50-200 \mathrm{ng} / \mathrm{ml}$ and the level of recommendation is 2(recommended) which means it can be used for individual dose adjustment ${ }^{11}$. The probability of EPS may be increased with levels above $200-250 \mathrm{ng} / \mathrm{ml}^{54}$.

High Dosing: Dose titration : For the treatment of schizophrenia in adults, ziprasidone should be initiated at $20.0 \mathrm{mg}$ twice daily, with subsequent dosage increases up to $80.0 \mathrm{mg}$ twice daily (Table 1 ). Dosing adjustments should occur in increments of $20.0 \mathrm{mg}$ twice daily at intervals no less than 2 days, with a maximum dose of $80.0 \mathrm{mg}$ twice daily.

FDA approved maximum dose is $160 \mathrm{mg} /$ day. Interestingly, the use of 120 to $160 \mathrm{mg}$ is associated with better adherence than lower dosages ${ }^{65}$. In a study completed at a state hospital, it was noted that $51.6 \%$ received a dosage higher than $160 \mathrm{mg} /$ day, and this was associated with improvement in symptoms and did not have significant side-effects. In the same study the average discharge (successful outcome) dose for ziprasidone was $206 \mathrm{mg}$ per day with patients having history of prior admissions and those who carried a diagnosis of schizophrenia getting higher dosages ${ }^{66}$. There have been studies reporting higher doses of ziprasidone up to 360 $\mathrm{mg} /$ day in forensic settings and in state hospitals $\mathrm{s}^{27,67,68,69}$. For titration of ziprasidone to higher doses, daily increases have been tolerated ${ }^{8}$.

\section{Iloperidone}

Pharmacodynamics: This requires a 4-day titration schedule due to its high a1 antagonism and risk for orthostasis. Antihypertensive agents, if combined should be executed with care due to this. Given its weaker affinity for D2 receptors, it appears to have a lower degree of EPS and hyperprolactinemia compared to risperidone and ziprasidone. It is one of the lowest EPS profile SGA available.

Iloperidone is metabolized into two metabolites, P88 and P95, with P88 being similar to iloperidone with its ability to cross blood brain barrier and binding to similar receptors as the parent compound. P95 on the other hand does not cross the blood brain barrier and has a different affinity profile and unlikely to contribute to clinical effects ${ }^{70}$.

Iloperidone has very low antagonistic affinities for the histamine $\mathrm{H} 1$ (less sedation and weight gain) and muscarinic M1 (less cognitive and gastrointestinal sideeffects). Iloperidone has been shown to prolong the QTc interval by $9 \mathrm{~ms}$ when it is administered at a maximum dose of $12 \mathrm{mg}$ twice daily and should be discontinued if QTc interval measures > $500 \mathrm{~ms}$. Similar to asenapine, paliperidone, ziprasidone and quetiapine, there is a warning about combining iloperidone with other medications that prolong the QT interval and in those with bradycardia, history of hypokalemia, hypomagnesemia, recent myocardial infarction, uncompensated heart failure or congenital QTc syndrome ${ }^{71}$.

Pharmacokinetics: Bioavailability is $100 \%$ and protein binding is 95\%. Iloperidone is a substrate for CYP2D6 with a half-life of 18 hours for CYP2D6 rapid metabolizers and 33 hours for slow metabolizers. Since it is also a substrate for CYP3A4, dose adjustment is needed when combining with drugs which are either inducers or inhibitors of these enzymes.

TDM: AGNP consensus guidelines reporta TDM of 5 to 10 $\mathrm{ng} / \mathrm{ml}$ with possible toxicity when plasma concentrations are above $20 \mathrm{ng} / \mathrm{ml}^{11}$. The recommendation level by AGNP is 3 (useful). TDM can be used to control whether plasma concentrations are plausible for a given oral dose. Clinical improvement may be attained by dose incrementation in non-responders who display plasma concentrations that are too low.

High Dosing: FDA approved maximum dose is $24 \mathrm{mg}$. It is a relatively newer and underutilized antipsychotic and has limited data for high dosing. For safety (not for efficacy) it has been tested up to $32 \mathrm{mg}^{72}$.

\section{Lurasidone}

Pharmacodynamics: Lurasidone has a high antagonistic affinity for the 5-HT2A as well as D2 receptor. It has a rather high EPS rate for akathisia reported in $14 \%$ of subjects receiving the $80 \mathrm{mg} /$ day dose. Despite the drug's high affinities for both receptors, the ratio of 5-HT2A blockade/D2 blockade is low which may explain the high akathisia rate. It has the lowest antagonistic affinity in class for the histamine $\mathrm{H} 1$ receptor, as well as, low antagonistic 
affinities for acetylcholine muscarinic M1 receptors and $\alpha 1$-adrenoceptors, suggesting low potential for weight gain, sedation, hypotension or cognitive dysfunction ${ }^{73}$. Lurasidone, like ziprasidone, has an advantage over other SGA with much less likelihood of metabolic side-effects (weight gain, dyslipidemia and diabetes) ${ }^{61,74}$.

Pharmacokinetics: Lurasidone has a 2-fold increase (18.0-38.0\%) in bioavailability when taken with meals and is recommended to be administered with at least $350 \mathrm{kcal}$ of food to ensure maximum absorption. Doubling of the dosage may be required in fasting states.

Lurasidone is a substrate for CYP3A4, and its levels are significantly affected by concomitant administration of CYP3A4 inducers and inhibitors. Its use is contraindicated in presence of strong inhibitors or inducers. When using with moderate inhibitors/inducers dose adjustment by reducing the dose to half when combining with CYP3A4 inhibitors and doubling the dosage in case of inducers may be necessary. Lurasidone is not a substrate for CYP1A2 and hence smoking should not affect dosing. As per one study Lurasidone's dose does not need to be adjusted for age or gender ${ }^{74}$.

Lurasidone is highly protein bound which leads to potential drug-drug interactions when combing with other protein bound drugs. Its half-life is affected by both hepatic and renal impairment, using a lower dose of $40 \mathrm{mg} /$ day in such populations is advisable ${ }^{75}$.

TDM: AGNP TDM consensus guideline for lurasidone is between $15-40 \mathrm{mg} / \mathrm{dl}$ and has a level of recommendation of 3 (useful). A relationship between plasma concentration and outcome is not yet demonstrated but aids in clinical problem solving.

High dosing: The FDA approved dose for lurasidone is up to $160 \mathrm{mg} /$ day. This is a newer antipsychotic and limited information is available regarding high dosage. Past studies have shown increasing side-effects with higher dosing, however one recent 6 week study found that administering the dose in the evening minimizes the risk of adverse effects $^{74}$. Higher dosages have been studied up to $600 \mathrm{mg}$ for safety reasons (QTc prolongation) but not for efficacy ${ }^{32}$.

\section{Quetiapine}

Pharmacodynamics: Quetiapine has a very low affinity (lowest among the SGA) for the D2 receptor and a relatively high affinity for the 5-HT2A receptor leading to possibly the lowest EPS rate in class and likelihood of causing hyperprolactinemia of the SGA discussed ${ }^{76}$. Quetiapine has two formulations, immediate release (IR) and extended release (XR).Quetiapine's active metabolite is norquetiapine which has a similar binding profile to its parent compound. $\mathrm{H} 1$ binding is one of the highest among the SGA leading to its sedative, weight gain propensity, as well as, its antianxiety properties. Quetiapine /norquetiapine more aggressively antagonizes 5HT2C which has antidepressant properties similar to mirtazapine. This property also predisposes to metabolic disorder. Research with quetiapine XR indicated that the risk of metabolic syndrome was equal to placebo at $150 \mathrm{mg} /$ day but doubled with doubling of the dose $\mathrm{e}^{77}$. This SGA also has potent norepinephrine reuptake inhibition (NRI) adding to its antidepressant profile. High antagonism of $\alpha 1$ receptors results in orthostasis, while antagonism of cholinergic receptors could cause constipation, dry mouth, changes in cognition, and vision. Along with asenapine, ziprasidone, paliperidone and iloperidone, quetiapine now carries a warning about QTc interval prolongation ${ }^{78}$.

Pharmacokinetics: Bioavailability of $9 \%$. It has a higher protein binding of $83 \%$ protein $^{79}$.

It undergoes metabolism in the liver and is a substrate for CYP3A4 enzymes. Use of an inducer requires increasing the dose five times while use of inhibitors requires a decrease of dose to one sixth ${ }^{78}$. There is significant reduction in CYP3A4 enzymes after age of $70^{80}$. Also there is some evidence that the elderly have a lesser oral clearance of the drug ${ }^{81}$. Thus, dose titration should be slower in elderly and daily total dose needs to be lower ${ }^{79}$. There is very little evidence if any that gender affects its metabolism. Elderly patients receiving 300-750 mg/day have a 30-50\% lower oral clearance of quetiapine when compared to younger patients on similar dose ${ }^{80}$.

TDM: The AGNP-TDM consensus guidelines propose a therapeutic range of $100-500 \mathrm{ng} / \mathrm{mL}$ and a level of 2 where TDM is recommended for dose titration for clinical problem solving. For all other SGA discussed, clinical effects usually occur at D2 occupancy of $60 \%$ and increasing the D2 occupancy above a certain threshold (usually 80\%) leads often to increases in EPS. However, for quetiapine, even doses up to $750 \mathrm{mg}$ lead only to 40 to $50 \%$ D2 occupancy. Also, plasma concentrations of quetiapine do not correlate with D2 occupancy and plasma concentrations of 800 $\mathrm{ng} / \mathrm{ml}$ had less than $60 \%$ occupancy and had an absence of EPS ${ }^{54}$. Finally, clinicians should be aware that if XR formulation was taken in the evening and blood drawn in the morning, expected concentrations are two fold higher than the trough levels.

High dosing: FDA approved maximum dose is $800 \mathrm{mg}$ /day. In a naturalistic study completed in state hospital systems, 40 percent of patients with chronic psychosis were on doses above $750 \mathrm{mg} /$ day $^{82}$. As noted above striatal D2 occupancy does not correlate with plasma concentration and high dosage are not associated with EPS. Based on the above, it is not surprising that there have been anecdotal reports of dosage use up to $2400 \mathrm{mg}$ when lower doses were felt not to be effective ${ }^{83}$. Although there is less likelihood of EPS, use of high dosage is limited by 
side-effects of sedation and other vegetative symptoms. Titration should be at a slower rate for these higher doses.

\section{Olanzapine}

Pharmacodynamics: Olanzapine is most similar in its pharmacodynamic properties to clozapine and has a relatively low affinity for D2 receptors and a stronger binding affinity to $5 \mathrm{HT} 2 \mathrm{~A}$ receptors. It has moderate affinity to block muscarinic receptors which may lead to dry mouth, constipation, blurred vision, urinary retention, memory problems, and confusion. $\mathrm{H} 1$ receptor blockade leads to remarkable sedation and weight gain. $\alpha 1$ receptor blockade may lead to hypotension and possible orthostasis. Among the discussed SGA, it carries one of the highest risks for metabolic adverse effects and is also implicated in directly causing diabetes mellitus type $2^{73,84}$.

Pharmacokinetics: This drug is extensively eliminated by first pass metabolism with over 40 percent metabolized before reaching systemic circulation. This leads to an oral bioavailability of 80 percent. It has a high protein binding of $93 \%$. It is metabolized hepatically to $10 \mathrm{~N}$ glucuronide. It is mainly metabolized by the UDP glucuronosyltransferase family, while metabolism through CYP2D6/CYP1A2 are minor pathways. Genetic variations in UDP glucuronosyltransferase lead to interindividual variability in clinical effects. Concomitant use of inducers (smoking) or inhibitors (fluvoxamine) of CYP1A2 may influence plasma concentrations. Smokers and men show a greater clearance and thus a lower plasma concentration than nonsmokers and women ${ }^{85}$. Smoking cessation may be associated within a few days of an increase in side effects from olanzapine as its plasma levels have likely increased.

TDM: AGNP TDM consensus guidelines recommends plasma concentrations of $20-50 \mathrm{ng} / \mathrm{ml}$ and the level of recommendation is 1 (strongly recommended) as there is significant evidence that plasma concentrations are related to receptor occupancy and clinical outcomes ${ }^{86,87}$. Lab alert levels are above $150 \mathrm{ng} / \mathrm{ml}$ and are associated with higher rates of $\mathrm{EPS}^{11,54}$. There is large intra and interpatient variability with plasma olanzapine concentrations. The intra-patient differences are accounted by difference in daily dose, duration of treatment, smoking status etc. The plasma concentration/dose ratio accumulation peak after 4 months is $31 \%$ above baseline and $47 \%$ after 18 months with no clear plateau. It appears that both CYP inhibition and DNA regulatory mechanisms are involved in metabolism. The interpatient factors are genetic variations in enzymes, gender etc. Long term TDM can thus optimize treatment. TDM of 15-20 should be targeted for patients with schizophrenia ${ }^{54}$.

High dosing: The FDA recommended dose is $10-20 \mathrm{mg} /$ day. Up to this dose, the $\mathrm{D} 2$ receptor occupancy varies from 71 to $80 \%{ }^{54}$. A study in patients receiving olanzapine up to
$45 \mathrm{mg}$ found a dose dependent increase in D2 occupancy and patients tended not to exhibit any EPS ${ }^{88}$. A state hospital study found that doses often exceeding $20 \mathrm{mg}$ were used in more than 50 percent of patients. Higher doses of 40-60 mg appear to be more useful with more aggressive patients, who have higher levels of psychopathology and who are generally treatment resistant ${ }^{89}$. Interestingly, a follow up prospective study with a small sample size and no placebo group demonstrated no improved efficacy and higher risk of weight gain and hyperprolactinemia associated with the use of higher doses ${ }^{90}$. Yet another study found no statistically significant difference between 20 and $40 \mathrm{mg}$, but did find that severely ill patients had better responses while on higher doses ${ }^{91}$. Some forensic settings have reported dosage as high as $90 \mathrm{mg} /$ day in treatment resistant patients ${ }^{1}$.

\section{Asenapine}

Pharmacodynamics: Asenapine antagonizes 5-HT2A with a 20 times higher affinity (one of the highest among SGA) as compared to D2 receptor antagonism with low potential for EPS. Its remarkably high affinity for the H1 receptor may lead to sedation and/or some weight gain. It has low affinity for cholinergic receptors. It may also prolong the QTc interval and hence caution is needed in patients with past history of cardiac disease or current use of QTc prolonging medications.

Pharmacokinetics: Asenapine is the only SGA administered sublingually and it dissolves in seconds. Bioavailability increases from $5 \%$ to $35 \%$ when the drug is taken sublingually and falls significantly if patient swallows it whole or rinses his/her mouth out too quickly after taking it sublingually ${ }^{4}$. Nothing else should be taken orally for 10 minutes following dosing to allow for maximum mucosal absorption. Asenapine is metabolized by glucuronidation by UGT1A4, and oxidation by CYP1A2, CYP3A4 and CYP2D6 ${ }^{24}$. Hence care needs to be taken while combining this drug with inducers or inhibitors of these enzymes.

TDM: The AGNP-TDM consensus guidelines suggest a therapeutic range of $2-5 \mathrm{ng} / \mathrm{ml}$. TDM is potentially useful but should be restricted to special populations as plasma concentration has not correlated with clinical response as of yet ${ }^{11,24}$.

High Dosing: High dosing has not been well studied, nor reported in the literature.

\section{Aripiprazole}

Pharmacodynamics: Aripiprazole is a partial D2 and D3 agonist and a 5HT2A antagonist. This D2, D3 partial agonism is shared by two other newer drugs, cariprazine and brexpiprazole. As psychosis is felt to occur as a result of excessive dopaminergic neuronal firing, a partial agonist 
will still afford a net diminishing of neuronal firing as it acts less than a full agonist (endogenous dopamine). Antipsychotic effects occur at 60-80 percent D2 occupancy. Due to this unique binding profile clinicians have to balance its dosing. On one hand, higher doses are needed to overcome the partial D2 agonism for antipsychotic effects to occur, while on the other hand, very high doses could theoretically make it less effective ${ }^{73}$. Also, in the presence of another D2 antagonist (antipsychotic) aripiprazole and similar drugs would act as a partial D2 agonist. With a very high D2 affinity, this drug could easily displace other antipsychotics so that antipsychotic polypharmacy may actually worsen psychosis ${ }^{67}$. D3 partial agonism does not add to the antipsychotic effects but may be helpful in improving cognition and as an antidepressant theoretically.

The two notable side-effects with aripiprazole are mild to moderate akathisia (23\% of patients) and some weight gain $^{92}$. The high potential for akathisia may be due to high D2 affinity as well as enhanced monoaminergic activity. Weight gain and consequent cardiometabolic sequalae may be due to moderate affinity to antagonize $\mathrm{H} 1$ receptors. Weight gain potential is highest for brexpiprazole, followed by aripiprazole, and then cariprazine ${ }^{93}$. Moderate antagonism of $\alpha 1$ receptors would account for its hypotension sideeffects. The M1 antagonism is very weak leading to minimal anticholinergic side-effects. As compared to other D2 partial agonists, it has lower potential for EPS and dystonia but has a higher potential for akathisia.

Pharmacokinetics: Bioavailability is $90 \%$ and protein binding is $99 \%$. It is metabolized in the liver via CYP3A4 and CYP2D6 enzymes and its major active metabolite dehydro-aripiprazole represents $45 \%$ of resultant plasma aripiprazole concentrations ${ }^{11}$. Clinicians have to be mindful about the CYP2D6 genetic variations leading to interpatient variability in metabolization and must be careful during concomitant use of inducers or inhibitors of either enzymes and dosing needs to be halved when used concomitantly with a CYP2D6 inhibitors. Akathisia can occur with concomitant use of SSRI and SNRI due to cumulative monoaminergic effects ${ }^{72}$.

Age gender, hepatic, renal impairment, and smoking do not significantly affect metabolism ${ }^{94}$.

TDM: AGNP TDM consensus guideline for TDM is 150$500 \mathrm{ng} / \mathrm{ml}$, and it calculates the concentration of aripiprazole as well as its active metabolite dehydroaripiprazole ${ }^{11}$. The recommendation level is 2 (recommended). Interestingly, the CYP2D6 genotypes significantly affected the plasma concentration of aripiprazole (but not of dehydroaripiprazole) in Asian patients ${ }^{95}$.

High dosing: The FDA approved highest dose is 30 $\mathrm{mg} /$ day and there is not much data supporting dosing above this. Some data has suggested a state dependent dosing for aripiprazole with augmentation for treatment resistant depression benefitting from a lower dose of $2 \mathrm{mg}$, psychosis or schizophrenia being treated between the dose of 15 to $30 \mathrm{mg}$, and a starting loading dose of $30 \mathrm{mg}$ for patients with acute mania ${ }^{72}$. Some studies also suggest that treatment of psychosis or schizophrenia requires nearly complete saturation of D2 receptors, with doses of $15 \mathrm{mg}$ leading to at least therapeutic D2 occupancy correlating with plasma concentration of $100 \mathrm{ng} / \mathrm{ml}$ or higher. Doses of $30 \mathrm{mg} /$ day will lead to this level in nearly every patient ${ }^{54}$. Another review reported a $10 \%$ above label dosing in NY State hospitals ${ }^{82}$. These higher doses are usually used in acute mania or treatment resistant schizophrenia. Doses of $40 \mathrm{mg}$ have $96.8 \%$ D2 occupancy so further increase may not lead to clinical improvement. Dosing may follow a U shaped curve and sometimes super dosing might actually be less effective with higher adverse effect profile ${ }^{72}$.

\section{Brexpiprazole}

Pharmacodynamics: As noted above, brexpiprazole also is a partial D2 and D3 agonist. Comparatively, it has the highest antagonism for 5HT2a which lowers the potential for EPS, and in fact, akathisia is known to be 50 percent less as compared to aripiprazole and cariprazine ${ }^{96,97}$. It has the strongest binding to $\mathrm{H} 1$ receptors and is most likely to cause increased appetite among the three partial agonist drugs, and so has the greatest potential for metabolic adverse-effects ${ }^{93,97}$. It also has the strongest $\alpha 1$ antagonism and consequent risk of elevated hypotension. Like the other two drugs it has very weak M1 binding.

Pharmacokinetics: Bioavailability is $95 \%$ and the protein binding is $99 \%$. It has a long half-life of 91 hours and is primarily metabolized by the liver. It is substrate for CYP3A4 and CYP2D6. As for aripiprazole, doses need to be adjusted for poor/rapid metabolizers of CYP2D6 or if given with strong inducers or inhibitors of either of this enzyme. If given with a strong CYP2D6 or CYP3A4 inhibitor halving the dose, while in presence of a strong CYP3A4 inducers doubling the dose of the drug is recommended ${ }^{97}$.

Brexpiprazole's protein binding is not affected by warfarin, diazepam, or digoxin dosing. Metabolism is mediated primarily by the CYP3A4 and CYP2D6 enzymes and its major metabolite is DM-3411. This metabolite does not seem to play a role in clinical improvement ${ }^{97}$.

TDM: The AGNP-consensus guideline TDM are 40-140 $\mathrm{ng} / \mathrm{ml}$. The level of recommendation is 3 (useful). Plasma concentration are not affected by its major metabolite DM3411

High dosing: This newer SGA has little data in this area.

\section{Cariprazine}

Pharmacodynamics: This is the newest antipsychotic 
to receive FDA approval and also is a partial D2 and D3 agonist. It binds to 5HT2A but the affinity to this receptor is lower, leading to increased vulnerability for EPS which has been the most common side-effects associated with high dosing. In fact, among the three partial agonists, cariprazine has the highest potential for EPS (except akathisia) and somnolence ${ }^{93}$. It does antagonize the $\mathrm{H} 1$ receptor leading to more sedation and weight gain. As mentioned above, the antagonism of M1 receptors is extremely weak. The possibility of orthostasis is low due to weak $\alpha 1$-adrenergic receptor binding.

Pharmacokinetics: Cariprazine has 100\% bioavailability and high protein binding. It is metabolized in the liver by CYP3A4 enzymes to two active metabolites, didesmethyl cariprazine (DDCAR) and desmethyl cariprazine (DCAR). It has the longest half-life among the three partial agonists of 3 weeks. The active metabolites are similar to the parent compound in that they have similar binding profiles and longer half-lives. Care should be taken when combing with CYP3A4 inhibitors or inducers, with recommendations of halving the dose of cariprazine when taken along with a strong CYP3A4 inhibitor ${ }^{98}$.

This has longest SGA half-life (if its active metabolite is included, equaling as long as 3 weeks); aripiprazole and brexpiprazole follow with 94 and $91 \mathrm{~h}$, respectively.

TDM: The AGNP TDM consensus guideline is $10-20$ $\mathrm{ng} / \mathrm{ml}$ and the level of recommendation is 3 (useful). TDM can be used for special indications or problem solving. Interestingly, one of the two major active metabolites of cariprazine, (DDCAR) approaches steady state concentrations around 4-8 weeks, with a half-life between 1-3 weeks, so that any dose change would not reflect in the plasma concentrations immediately and may take weeks to establish. Thus, it would be advisable to monitor for acute side-effects for a prolonged clinical period.

High dosing: This has not been well studied for this newest SGA.

\section{Conclusions}

This paper attempts to update the reader regarding clinically relevant concepts of SGA pharmacokinetics, pharmacodynamics, therapeutic drug monitoring, and dosing equivalencies as advanced practice ideas whereby a clinician may better monitor SGA use and make improved clinical decisions on a per patient basis. In addition, there is a micro-review of each SGA which suggests that they are simply not "me-too drugs" but each may have a unique clinical identity that may better serve patients at the level of the individual patient being seen. These concepts may help clinicians decide amongst a variety of SGA, but more importantly teach the clinician how to dose and utilize each agent to its fullest extent.

\section{Conflict of interests}

The authors declared no potential conflicts of interest with respect to the research, authorship, and/or publication of this article.

\section{Acknowledgements}

Neither author reports any conflict of interest and no funding was utilized in the writing of this paper.

\section{References}

1. Morrissette DA, Stahl SM. Treating the violent patient with psychosis or impulsivity utilizing antipsychotic polypharmacy and high-dose monotherapy. doi:10.1017/S1092852914000388

2. Citrome L, Volavka J. Optimal dosing of atypical antipsychotics in adults: A review of the current evidence. Harv Rev Psychiatry. 2002; 10(5): 280-291. doi:10.1080/10673220216279

3. Solmi M, Murru A, Pacchiarotti I, et al. Safety, tolerability, and risks associated with first- and second-generation antipsychotics: a stateof-the-art clinical review. Ther Clin Risk Manag. 2017; 13: 757-777. doi:10.2147/TCRM.S117321

4. Dell RSO, Schwartz TL. THE SECOND GENERATION ANTIPSYCHOTICS : A REVIEW OF CURRENT TREATMENT INDICATIONS AND DOSING STRATEGIES.

5. McDonagh MS, Dana T, Selph S, et al. Treatments for Schizophrenia in Adults: A Systematic Review. Agency for Healthcare Research and Quality (US); 2017. http://www.ncbi.nlm.nih.gov/ pubmed/29537779. Accessed June 21, 2018.

6. Patterson TL, Leeuwenkamp OR. Adjunctive psychosocial therapies for the treatment of schizophrenia. Schizophr Res. 2008; 100(1-3): 108-119. doi:10.1016/j.schres.2007.12.468

7. Guo X, Zhai J, Liu Z, et al. Effect of antipsychotic medication alone vs combined with psychosocial intervention on outcomes of early-stage schizophrenia: A randomized, 1-year study. Arch Gen Psychiatry. 2010; 67(9): 895-904. doi:10.1001/archgenpsychiatry.2010.105

8. Correll CU. From receptor pharmacology to improved outcomes: individualising the selection, dosing, and switching of antipsychotics. Eur Psychiatry. 2010; 25: S12-S21. doi:10.1016/S09249338(10)71701-6

9. Meyer JM. A rational approach to employing high plasma levels of antipsychotics for violence associated with schizophrenia: case vignettes. CNS Spectr. 2014; 19(5): 432-438. doi:10.1017/ S1092852914000236

10. Correll CU, Rummel-Kluge C, Corves C, et al. Antipsychotic combinations vs monotherapy in schizophrenia: a meta-analysis of randomized controlled trials. Schizophr Bull. 2009; 35(2): 443-457. doi:10.1093/schbul/sbn018

11. Hiemke AC, Bergemann N, Clement HW, et al. Consensus Guidelines for Therapeutic ... Pharmacopsychiatry Consensus Guidelines for Therapeutic Drug Monitoring in Neuropsychopharmacology: Update 2017 Hiemke C et al . Consensus Guidelines for Therapeutic ... Pharmacopsychiatry. 2017. https://www-thiemeconnect-com.libproxy2.upstate.edu/products/ejournals / pdf/10.1055/s-0043-116492.pdf. Accessed January 30, 2018.

12. Uchida H, Takeuchi H, Graff-Guerrero A, et al. Dopamine D2 Receptor Occupancy and Clinical Effects. J Clin Psychopharmacol. 2011; 31(4): 497-502. doi:10.1097/JCP.0b013e3182214aad

13. Nord M, Farde L. Antipsychotic occupancy of dopamine receptors in schizophrenia. CNS Neurosci Ther. 2011; 17(2): 97-103. doi:10.1111/ j.1755-5949.2010.00222.x 
14. Uchida $\mathrm{H}$, Takeuchi H, Graff-Guerrero A, et al. Predicting dopamine $\mathrm{D}_{2}$ receptor occupancy from plasma levels of antipsychotic drugs: a systematic review and pooled analysis. J Clin Psychopharmacol. 2011; 31(3): 318-325. doi:10.1097/JCP.0b013e318218d339

15. Kinirons MT, O'Mahony MS. Drug metabolism and ageing. $\mathrm{Br}$ J Clin Pharmacol. 2004; 57(5): 540-544. doi:10.1111/j.13652125.2004.02096.x

16. Damoiseaux VA, Proost JH, Jiawan VCR, et al. Sex differences in the pharmacokinetics of antidepressants: influence of female sex hormones and oral contraceptives. Clin Pharmacokinet. 2014; 53(6): 509-519. doi:10.1007/s40262-014-0145-2

17. Kokras N, Dalla C, Papadopoulou-Daifoti Z. Sex differences in pharmacokinetics of antidepressants. Expert Opin Drug Metab Toxicol. 2011; 7(2): 213-226. doi:10.1517/17425255.2011.544250

18. Castberg I, Westin AA, Skogvoll E, et al. Effects of age and gender on the serum levels of clozapine, olanzapine, risperidone, and quetiapine. Acta Psychiatr Scand. 2017; 136(5): 455-464. doi:10.1111/ acps.12794

19. Klotz U. Pharmacokinetics and drug metabolism in the elderly. Drug Metab Rev. 2009; 41(2): 67-76. doi:10.1080/03602530902722679

20. Zhou SF. Polymorphism of Human Cytochrome P450 2D6 and Its Clinical Significance. Clin Pharmacokinet. 2009; 48(11): 689-723. doi:10.2165/11318030-000000000-00000

21. Zhou SF. Polymorphism of Human Cytochrome P450 2D6 and Its Clinical Significance. Clin Pharmacokinet. 2009; 48(12): 761-804. doi:10.2165/11318070-000000000-00000

22. Zhou SF, Liu JP, Chowbay B. Polymorphism of human cytochrome P450 enzymes and its clinical impact. Drug Metab Rev. 2009; 41(2): 89-295. doi:10.1080/03602530902843483

23. Grundmann M, Kacirova I, Urinovska R. Therapeutic drug monitoring of atypical antipsychotic drugs. Acta Pharm. 2014; 64(4): 387-401. doi:10.2478/acph-2014-0036

24. Patteet L, Morrens M, Maudens KE, et al. Therapeutic drug monitoring of common antipsychotics. Ther Drug Monit. 2012; 34(6): 629-651. doi:10.1097/FTD.0b013e3182708ec5

25. PRESKORN SH. Clinically Important Differences in the Pharmacokinetics of the Ten Newer "Atypical" Antipsychotics. J Psychiatr Pract. 2012; 18(3): 199-204. doi:10.1097/01 pra.0000415076.28497.8e

26. Faber MS, Fuhr U. Time response of cytochrome P450 1A2 activity on cessation of heavy smoking. Clin Pharmacol Ther. 2004; 76(2): 178184. doi:10.1016/j.clpt.2004.04.003

27. Mauri MC, Volonteri LS, Colasanti A, et al. Clinical Pharmacokinetics of Atypical Antipsychotics. Clin Pharmacokinet. 2007; 46(5): 359-388. doi:10.2165/00003088-200746050-00001

28. Brandl EJ, Kennedy JL, Müller DJ. Pharmacogenetics of Antipsychotics. Can J Psychiatry. 2014; 59(2): 76-88. doi:10.1177/070674371405900203

29. Greenbaum L, Strous RD, Kanyas K, et al. Association of the RGS2 gene with extrapyramidal symptoms induced by treatment with antipsychotic medication. Pharmacogenet Genomics. 2007; 17(7): 519-528. doi:10.1097/FPC.0b013e32800ffbb4

30. Sim K, Su HC, Fujii S, et al. High-dose antipsychotic use in schizophrenia: a comparison between the 2001 and 2004 Research on East Asia Psychotropic Prescription (REAP) studies. Br J Clin Pharmacol. 2009; 67(1): 110-117. doi:10.1111/j.1365-2125.2008.03304.x

31. Lieberman JA, Stroup TS, McEvoy JP, et al. Effectiveness of antipsychotic drugs in patients with chronic schizophrenia. N Engl J Med. 2005; 353(12): 1209-1223. doi:10.1056/NEJMoa051688

32. Moore BA, Morrissette DA, Meyer JM, et al. Drug information update. Unconventional treatment strategies for schizophrenia: polypharmacy and heroic dosing. BJPsych Bull. 2017. doi:10.1192/ pb.bp.115.053223

33. Margetić B, Aukst Margetić B, Ivanec D, et al. What leads to high antipsychotic dosing in forensic patients with schizophrenia. CNS Spectr. 2017; (2017): 1-4. doi:10.1017/S1092852916000675

34. Roh D, Chang JG, Kim CH, et al. Antipsychotic polypharmacy and highdose prescription in schizophrenia: A 5-year comparison. Aust N Z J Psychiatry. 2014; 48(1): 52-60. doi:10.1177/0004867413488221

35. Lotrich FE, Pollock BG. Aging and clinical pharmacology: implications for antidepressants. J Clin Pharmacol. 2005; 45(10): 1106-1122. doi:10.1177/0091270005280297

36. Patel MX, Arista IA, Taylor M, et al. How to compare doses of different antipsychotics: A systematic review of methods. Schizophr Res. 2013; 149: 141-148. doi:10.1016/j.schres.2013.06.030

37. Davis JM. Dose equivalence of the antipsychotic drugs. J Psychiatr Res. 1974; 11: 65-69. http://www.ncbi.nlm.nih.gov/pubmed/4156792. Accessed March 27, 2018.

38. Leucht S, Samara M, Heres S, et al. Dose Equivalents for SecondGeneration Antipsychotic Drugs: The Classical Mean Dose Method. Schizophr Bull. 2015; 41(6): 1397-1402. doi:10.1093/schbul/sbv037

39. Woods SW. The Journal of Clinical Psychiatry. Vol 64. [Physicians Postgraduate Press]; 2003. http://www.psychiatrist.com/JCP/article/ Pages/2003/v64n06/v64n0607.aspx. Accessed March 27, 2018.

40. Leucht S, Samara M, Heres S, et al. Dose Equivalents for SecondGeneration Antipsychotics: The Minimum Effective Dose Method. Schizophr Bull. 2014; 40(2): 314-326. doi:10.1093/schbul/sbu001

41. Davis JM, Chen N. Dose Response and Dose Equivalence of Antipsychotics. J Clin Psychopharmacol. 2004; 24(2): 192-208. doi:10.1097/01.jcp.0000117422.05703.ae

42. WHO. Collaborating Centre for Drug Statistics Methodology. Oslo, Norway: ATC Index with DDDs; 2012.

43. Leucht S, Samara M, Heres S, et al. Dose Equivalents for Antipsychotic Drugs: The DDD Method. Schizophr Bull. 2016; 42(1): S90-S94. doi:10.1093/schbul/sbv167

44. Kane JM, Leucht S, Carpenter D, et al. Expert Consensus Panel for Optimizing Pharmacologic Treatment of Psychotic Disorders. The expert consensus guideline series. Optimizing pharmacologic treatment of psychotic disorders. Introduction: methods, commentary, and summary. J Clin Psychiatry. 2003; 64 Suppl 12: 5-19. http://www. ncbi.nlm.nih.gov/pubmed/14640142. Accessed August 9, 2018.

45. Andreasen NC, Pressler M, Nopoulos P, et al. Antipsychotic dose equivalents and dose-years: a standardized method for comparing exposure to different drugs. Biol Psychiatry. 2010; 67(3): 255-262. doi:10.1016/j.biopsych.2009.08.040

46. Gardner DM, Pharm D, Murphy AL, et al. International Consensus Study of Antipsychotic Dosing. 2010;(June): 686-693. doi:10.1176/ appi.ajp.2009.09060802

47. Kapur S, Langlois $X$, Vinken $P$, et al. The differential effects of atypical antipsychotics on prolactin elevation are explained by their differential blood-brain disposition: a pharmacological analysis in rats. J Pharmacol Exp Ther. 2002; 302(3): 1129-1134. doi:10.1124/ jpet.102.035303

48. Knegtering R, Baselmans P, Castelein S, et al. Predominant role of the 9-hydroxy metabolite of risperidone in elevating blood prolactin levels. Am J Psychiatry. 2005; 162(5): 1010-1012. doi:10.1176/appi. ajp.162.5.1010

49. Cabaleiro T, Ochoa D, López-Rodríguez R, et al. Effect of polymorphisms on the pharmacokinetics, pharmacodynamics, and safety of risperidone in healthy volunteers. Hum Psychopharmacol Clin Exp. 2014; 29(5): 459-469. doi:10.1002/hup.2420 
50. Aravagiri M, Marder S, Wirshing D, et al. Plasma Concentrations of Risperidone and its 9-Hydroxy Metabolite and their Relationship to Dose in Schizophrenic Patients: Simultaneous Determination by a High Performance Liquid Chromatography with Electrochemical Detection. Pharmacopsychiatry. 1998; 31(03): 102-109. doi:10.1055/s-2007-979308

51. Remmerie BMM, Sips LLA, de Vries R, et al. Validated method for the determination of risperidone and 9-hydroxyrisperidone in human plasma by liquid chromatography-tandem mass spectrometry. J Chromatogr B Analyt Technol Biomed Life Sci. 2003; 783(2): 461-472. http://www.ncbi.nlm.nih.gov/pubmed/12482489. Accessed March $27,2018$.

52. Peuskens J. Risperidone in the treatment of patients with chronic schizophrenia: a multi-national, multi-centre, double-blind, parallelgroup study versus haloperidol. Risperidone Study Group. Br J Psychiatry. 1995; 166(6): 712-26; discussion 727-33. http://www. ncbi.nlm.nih.gov/pubmed/7545060. Accessed March 27, 2018.

53. Darby JK, Pasta DJ, Wilson MG, et al. Long-term therapeutic drug monitoring of risperidone and olanzapine identifies altered steadystate pharmacokinetics: a clinical, two-group, naturalistic study. Clin Drug Investig. 2008; 28(9): 553-564. http://www.ncbi.nlm.nih.gov/ pubmed/18666802. Accessed March 1, 2018.

54. Gründer G, Hiemke C, Paulzen M, et al. Therapeutic Plasma Concentrations of Antidepressants and Antipsychotics: Lessons from PET Imaging. Pharmacopsychiatry. 2011; 44(06): 236-248. doi:10.1055/s-0031-1286282

55. Morrissette DA, Stahl SM. Treating the violent patient with psychosis or impulsivity utilizing antipsychotic polypharmacy and high-dose monotherapy. CNS Spectr. 2014; 19(05): 439-448. doi:10.1017/ S1092852914000388

56. Marder SR, Meibach RC. Risperidone in the treatment of schizophrenia. Am J Psychiatry. 1994; 151(6): 825-835. doi:10.1176/ajp.151.6.825

57. Jones MP, Nicholl D, Trakas K. Efficacy and tolerability of paliperidone ER and other oral atypical antipsychotics in schizophrenia. Int J Clin Pharmacol Ther. 2010; 48(6): 383-399. http://www.ncbi.nlm.nih. gov/pubmed/20497747. Accessed January 29, 2018.

58. Conley R, Gupta SK, Sathyan G. Clinical spectrum of the osmoticcontrolled release oral delivery system (OROS), an advanced oral delivery form. Curr Med Res Opin. 2006; 22(10): 1879-1892. doi:10.1185/030079906X132613

59. Citrome L. Oral paliperidone extended-release: chemistry, pharmacodynamics, pharmacokinetics and metabolism, clinical efficacy, safety and tolerability. Expert Opin Drug Metab Toxicol. 2012; 8(7): 873-888. doi:10.1517/17425255.2012.693160

60. Caley CF, Cooper CK. Ziprasidone: the fifth atypical antipsychotic. Ann Pharmacother. 2002; 36(5): 839-851. doi:10.1345/aph.1A053

61. Chen Y, Bobo WV, Watts $\mathrm{K}$, et al. Comparative effectiveness of switching antipsychotic drug treatment to aripiprazole or ziprasidone for improving metabolic profile and atherogenic dyslipidemia: a 12-month, prospective, open-label study. J Psychopharmacol. 2012; 26(9): 1201-1210. doi:10.1177/0269881111430748

62. Park S, Yi K, Kim MS, et al. Effects of ziprasidone and olanzapine on body composition and metabolic parameters: an open-label comparative pilot study. Behav Brain Funct. 2013; 9(1): 27. doi:10.1186/1744-9081-9-27

63. Stimmel GL, Gutierrez MA, Lee V.Ziprasidone: an atypical antipsychotic drug for the treatment of schizophrenia. Clin Ther. 2002; 24(1): 2137. http://www.ncbi.nlm.nih.gov/pubmed/11833834. Accessed March 28, 2018.

64. Miceli JJ, Glue P, Alderman J, et al. The effect of food on the absorption of oral ziprasidone. Psychopharmacol Bull. 2007; 40(3): 58-68. http://www.ncbi.nlm.nih.gov/pubmed/18007569. Accessed March 28, 2018.
65. Citrome L, Reist C, Palmer L, et al. Impact of real-world ziprasidone dosing on treatment discontinuation rates in patients with schizophrenia or bipolar disorder. Schizophr Res. 2009; 115(2-3): 115-120. doi:10.1016/j.schres.2009.09.023

66. Citrome L, Jaffe A, Levine J, et al. Ziprasidone Dosing in State Hospitals How Dosing of Ziprasidone in a State Hospital System Differs From Product Labeling. J Clin Psychiatry. 2009; 70770(7): 975-982. http:// www-psychiatrist-com.libproxy1.upstate.edu/JCP/article/_layouts/ ppp.psych.controls/BinaryViewer.ashx?Article=/JCP/article/ Pages $/ 2009 / \mathrm{v} 70 \mathrm{n} 07 / \mathrm{v} 70 \mathrm{n} 0705$. aspx\&Type=Article. $\quad$ Accessed January 20, 2018.

67. Stahl SM. Stahl's Essential Psychopharmacology: Neuroscientific Basis and Practical Applications. 4th edn. Cambridge University Press; 2013.

68. Schwartz TL, Stahl SM. Treatment Strategies for Dosing the Second Generation Antipsychotics. doi:10.1111/j.1755-5949.2011.00234.x

69. Barnes TRE, Paton C. Antipsychotic Polypharmacy in Schizophrenia. CNS Drugs. 2011; 25(5): 383-399. doi:10.2165/11587810000000000-00000

70. Subramanian N, Kalkman HO. Receptor profile of P88-8991 and P95-12113, metabolites of the novel antipsychotic iloperidone. Prog Neuropsychopharmacol Biol Psychiatry. 2002; 26(3): 553-560. http://www.ncbi.nlm.nih.gov/pubmed/11999907. Accessed March 28, 2018.

71. FANAPT (iloperidone) tablet, FANAPT (iloperidone) kit DailyMed. Bethesda (MD): National Library of Medicine (US).

72. Cutler A, Ball S, Stahl SM. Dosing atypical antipsychotics. CNS Spectr. 2008; 13(5 Suppl 9): 1-16. http://www.ncbi.nlm.nih.gov/ pubmed/18496483. Accessed January 29, 2018.

73. Schwartz T, Bedynerman K. Utilizing pharmacodynamic properties of second-generation antipsychotics to guide treatment. Drugs of Today. 2012; 48(4): 283-292. doi:10.1358/dot.2012.48.4.1745225

74. LATUDA- lurasidone hydrochloride tablet, film coated DailyMed. Bethesda (MD): National Library of Medicine (US). http://dailymed. nlm.nih.gov/dailymed/drugInfo.cfm?id=5420.

75. Caccia S. Pharmacokinetics and metabolism update for some recent antipsychotics. Expert Opin Drug Metab Toxicol. 2011; 7(7): 829-846. doi:10.1517/17425255.2011.575061

76. Tarsy D, Baldessarini RJ, Tarazi FI. Effects of newer antipsychotics on extrapyramidal function. CNS Drugs. 2002; 16(1): 23-45. http://www. ncbi.nlm.nih.gov/pubmed/11772117. Accessed March 28, 2018.

77. Peuskens J. The management of schizophrenia: focus on extendedrelease quetiapine fumarate. Neuropsychiatr Dis Treat. 2011; 7: 549564. doi:10.2147/NDT.S3380

78. SEROQUEL XR- quetiapine fumarate tablet, extended release SEROQUEL XR- quetiapine fumarate. DailyMed. Bethesda (MD): National Library of Medicine (US). http://dailymed.nlm.nih.gov/ dailymed/drugInfo.cfm?id=5420.\%0A.

79. DeVane CL, Nemeroff CB. Clinical Pharmacokinetics of Quetiapine. Clin Pharmacokinet. 2001; 40(7): 509-522. doi:10.2165/00003088200140070-00003

80. Grimm SW, Richtand NM, Winter HR, et al. Effects of cytochrome P450 3A modulators ketoconazole and carbamazepine on quetiapine pharmacokinetics. Br J Clin Pharmacol. 2006; 61(1): 58-69. doi:10.1111/j.1365-2125.2005.02507.x

81. Sotaniemi EA, Arranto AJ, Pelkonen 0, et al. Age and cytochrome P450-linked drug metabolism in humans: An analysis of 226 subjects with equal histopathologic conditions*. Clin Pharmacol Ther. 1997; 61(3): 331-339. doi:10.1016/S0009-9236(97)90166-1

82. Citrome L, Jaffe A, Levine J. Datapoints: The ups and downs of dosing second-generation antipsychotics. Psychiatr Serv. 2007; 58(1): 11. doi:10.1176/ps.2007.58.1.12 
83. Citrome L, Jaffe A, Levine J, et al. Dosing of quetiapine in schizophrenia: how clinical practice differs from registration studies. J Clin Psychiatry. 2005; 66(12): 1512-1516. http://www.ncbi.nlm.nih.gov/ pubmed/16401150. Accessed March 28, 2018.

84. ZYPREXA - olanzapine tablet ZYPREXA ZYDIS - olanzapine tablet orally disintegrating ZYPREXA INTRAMUSCULAR - olanzapine injection, powder, for solution. DailyMed. Bethesda (MD): National Library of Medicine (US).

85. Callaghan JT, Bergstrom RF, Ptak LR, et al. Olanzapine. Clin Pharmacokinet. 1999; 37(3): 177-193. doi:10.2165/00003088199937030-00001

86. Mauri MC, Steinhilber CPC, Marino R, et al. Clinical outcome and olanzapine plasma levels in acute schizophrenia. Eur Psychiatry. 2005; 20(1): 55-60. doi:10.1016/j.eurpsy.2004.09.009

87. Kapur S, Zipursky RB, Remington G, et al. 5-HT2 and D2 receptor occupancy of olanzapine in schizophrenia: a PET investigation. Am J Psychiatry. 1998; 155(7): 921-928. doi:10.1176/ajp.155.7.921

88. Attarbaschi T, Sacher J, Geiss-Granadia T, et al. Striatal D(2) receptor occupancy in bipolar patients treated with olanzapine. Eur Neuropsychopharmacol. 2007; 17(2): 102-107. doi:10.1016/j. euroneuro.2006.07.001

89. Citrome L, Kantrowitz JT. Olanzapine dosing above the licensed range is more efficacious than lower doses: fact or fiction. Expert Rev Neurother. 2009; 9(7): 1045-1058. doi:10.1586/ern.09.54

90. Citrome L, Stauffer VL, Chen L, et al. Olanzapine Plasma Concentrations After Treatment With 10,20, and $40 \mathrm{mg} / \mathrm{d}$ in Patients With Schizophrenia. J Clin Psychopharmacol. 2009; 29(3): 278-283. doi:10.1097/JCP.0b013e3181a289cb

91. Kinon BJ, Volavka J, Stauffer V, et al. Standard and higher dose of olanzapine in patients with schizophrenia or schizoaffective disorder: a randomized, double-blind, fixed-dose study. J Clin Psychopharmacol. 2008; 28(4): 392-400. doi:10.1097/JCP.0b013e31817e63a5

92. Han C, Wang SM, Kato M, et al. Second-generation antipsychotics in the treatment of major depressive disorder: current evidence. Expert Rev Neurother. 2013; 13(7): 851-870. doi:10.1586/14737175.2013 .811901

93. Citrome L. The ABC's of dopamine receptor partial agonists aripiprazole, brexpiprazole and cariprazine: the 15-min challenge to sort these agents out. Int J Clin Pract. 2015; 69(11): 1211-1220. doi:10.1111/ijcp.12752
94. Mallikaarjun S, Salazar DE, Bramer SL. Pharmacokinetics, Tolerability, and Safety of Aripiprazole following Multiple Oral Dosing in Normal Healthy Volunteers. J Clin Pharmacol. 2004; 44(2): 179-187. doi:10.1177/0091270003261901

95. Suzuki T, Mihara K, Nakamura A, et al. Effects of genetic polymorphisms of CYP2D6, CYP3A5, and ABCB1 on the steadystate plasma concentrations of aripiprazole and its active metabolite, dehydroaripiprazole, in Japanese patients with schizophrenia. Ther Drug Monit. 2014; 36(5): 651-655. doi:10.1097/ FTD.0000000000000070

96. Maeda K, Sugino H, Akazawa H, et al. Brexpiprazole I: in vitro and in vivo characterization of a novel serotonin-dopamine activity modulator. J Pharmacol Exp Ther. 2014; 350(3): 589-604. doi:10.1124/jpet.114.213793

97. REXULTI- brexpiprazole tablet. DailyMed. Bethesda (MD): National Library of Medicine (US). http://dailymed.nlm.nih.gov/dailymed/ drugInfo.cfm?id=5420.

98. VRAYLAR- cariprazine capsule, gelatin coated DailyMed. Bethesda (MD): National Library of Medicine (US).

99. Citrome L, Bilder RM, Volavka J. Managing treatment-resistant schizophrenia: evidence from randomized clinical trials. J Psychiatr Pract. 2002; 8(4): 205-215. http://ovidsp.ovid.com/ovidweb. cgi?T=JS\&PAGE=reference $\& D=$ prem\&NEWS $=N \& A N=15985880$.

100. Stahl SM, Morrissette DA. Should High Dose or Very Long-Term Antipsychotic Monotherapy Be Considered Before Antipsychotic Polypharmacy? In: Polypharmacy in Psychiatry Practice, Volume I. Dordrecht: Springer Netherlands; 2013: 107-125. doi:10.1007/97894-007-5805-6_5

101. Andreasen NC, Pressler M, Nopoulos P, et al. Antipsychotic dose equivalents and dose-years: a standardized method for comparing exposure to different drugs. Biol Psychiatry. 2010; 67(3): 255-262. doi:10.1016/j.biopsych.2009.08.040

102. Leucht S, Samara M, Heres S, et al. Dose Equivalents for SecondGeneration Antipsychotic Drugs: The Classical Mean Dose Method. Schizophr Bull. 2015; 41(6): 1397-1402. doi:10.1093/schbul/ sbv037

103. Davis JM, Chen N. Dose response and dose equivalence of antipsychotics. J Clin Psychopharmacol. 2004; 24(2): 192-208. http://www. ncbi.nlm.nih.gov/pubmed/15206667. Accessed January 30, 2018. 